\title{
DNA packaging proteins Glom and Glom2 coordinately organize the mitochondrial nucleoid of Physarum Polycephalum
}

Kie Itoh ${ }^{\mathrm{a}, \mathrm{b}, \mathrm{c} *}$, Akiko Izumi ${ }^{\mathrm{c}}$, Toshiyuki Mori ${ }^{\mathrm{d}}$, Naoshi Dohmae ${ }^{\mathrm{e}}$, Ryoko Yui ${ }^{\mathrm{a}}$, Katsura Maeda-Sano ${ }^{\mathrm{c}, \mathrm{f}}$,

Yuki Shirai ${ }^{\mathrm{c}}$, Masahiro M. Kanaoka ${ }^{\mathrm{a}}$, Tsuneyoshi Kuroiwa ${ }^{\mathrm{g}}$, Tetsuya Higashiyama ${ }^{\mathrm{a}}$, Mamoru Sugita ${ }^{\mathrm{a}}$, Kimiko Murakami-Murofushic ${ }^{\mathrm{c}}$, Shigeyuki Kawano ${ }^{\mathrm{b}}$ and Narie Sasaki ${ }^{\mathrm{a}, \mathrm{c} *}$

${ }^{\mathrm{a} D i v i s i o n}$ of Biological Science, Graduate School of Science, Nagoya University, Nagoya, Aichi 464-8602, Japan

${ }^{\mathrm{b}}$ Department of Integrated Biosciences, Graduate School of Frontier Sciences, University of Tokyo, Kashiwa, Chiba 277-8562, Japan

${ }^{c}$ Department of Biology, Faculty of Science, Ochanomizu University, Bunkyo-ku, Tokyo 112-0012, Japan

${ }^{\mathrm{d}}$ Miyagishima Initiative Research Unit, Advanced Science Institute, RIKEN, Wako, Saitama 351-0198, Japan

${ }^{\mathrm{e}}$ Biomolecular Characterization Team, Advanced Science Institute, RIKEN, Wako, Saitama 351-0198, Japan

${ }^{\mathrm{f}}$ Department of Biomedical Chemistry, Graduate School of Medicine, University of Tokyo, Bunkyo-ku, Tokyo 113-0033, Japan

${ }^{\mathrm{g}}$ Research Information Center for Extremophiles, Graduate School of Science, Rikkyo (St. Paul's) University, Toshima-ku, Tokyo 171-8501, Japan

\section{*Corresponding authors:}

Division of Biological Science, Graduate School of Science, Nagoya University, Furo-cho, Nagoya, Aichi 464-8602, Japan., Tel: +81-52-789-3087, Fax: +81-52-789-3081, kie@gene.nagoya-u.ac.jp (K. Itoh) / Tel • Fax: +81-52-774-6402, narie@bio.nagoya-u.ac.jp (N. Sasaki) 


\title{
Keywords:
}

mitochondrial nucleoid, DNA packaging protein, Physarum polycephalum

\begin{abstract}
Abbreviations:
mtDNA, mitochondrial DNA; mt-nucleoid, mitochondrial nucleoid; HMG, high-mobility group; $\mathrm{MO}(\mathrm{s})$, morpholino antisense oligo(s); inv., inverted oligo
\end{abstract}

\begin{abstract}
1 Mitochondrial DNA (mtDNA) is generally packaged into the mitochondrial nucleoid 2 (mt-nucleoid) by a high-mobility group (HMG) protein. Glom is a mtDNA-packaging HMG 3 protein in Physarum polycephalum. Here we identified a new mtDNA-packaging protein,

4 Glom2, which had a region homologous with yeast Mgm101. Glom2 could bind to entire 5 mtDNA and worked synergistically with Glom for condensation of mtDNA in vitro.

6 Down-regulation of Glom2 enhanced the alteration of mt-nucleoids morphology and the loss of 7 mtDNA induced by down-regulation of Glom, and impaired mRNA accumulation of some 8 mtDNA-encoded genes. These data suggest that Glom2 may organize the mt-nucleoid 9 coordinately with Glom.
\end{abstract}




\section{1. Introduction}

2 The mitochondrion is an important organelle that produces the energy for cell viability.

3 This organelle possesses its own DNA, termed mitochondrial DNA (mtDNA), which encodes

4 essential components of the respiratory chain for the synthesis of ATP. Faithful maintenance of

5 mtDNA is necessary for the cell. MtDNA is packed into highly organized structures called

6 mitochondrial nucleoids (mt-nucleoids) containing many proteins (Kuroiwa, 1982; Kucej and

7 Butow, 2007; Spelbrink, 2010). In the eukaryotic nucleus, genomic DNA is organized into

8 repeating nucleosomal units composed of histones and their 1.7-turns around DNA

9 (Khorasanizadeh, 2004). However, how the structure of the mt-nucleoid is packaged and

10 organized is not known.

11 The high-mobility group (HMG) proteins containing two HMG boxes are major protein 12 components of the mt-nucleoid in many species, including animals, fungi, and slime mold

13 (Diffley and Stillman, 1991; Antoshechkin and Bogenhagen, 1995; Larsson et al., 1996;

14 Takamatsu et al., 2002; Sasaki et al., 2003). An exception has only been reported in

15 mitochondria (kinetoplasts) of the tripanosomatid Crithidia fasciculata, in which four histone

16 H1-like proteins are major protein components of the mt-nucleoid (Xu et al., 1996; Hines and

17 Ray, 1998). These proteins are highly basic and have the ability to directly bind to mtDNA with

18 no sequence specificity. Studies have estimated that sufficient Abf2 and TFAM, which are

19 mitochondrial HMG proteins in yeast and animals, respectively, exist to bind to every 15-30

20 and 10-20 bp of mtDNA (Diffley and Stillman, 1991, 1992; Takamatsu et al., 2002; Ekstrand et

21 al., 2004). These HMG proteins can entirely cover mtDNA because one molecule occupies

22 25-30 bp of mtDNA (Fisher and Clayton, 1988; Diffley and Stillman, 1992; Antoshechkin and

23 Bogenhagen, 1995). Abf2 and TFAM can bend and wrap DNA, and package it into a condensed

24 structure in vitro (Brewer et al., 2003; Friddle et al., 2004; Kaufman et al., 2007). These

25 properties indicate that mitochondrial HMG proteins play an important role in mtDNA 
1 packaging, similar to histones in the nucleus. In addition to their role in organizing the

2 mt-nucleoid, mtDNA packaging proteins participate in the overall regulation of DNA function

3 by binding to entire mtDNA. For example, knockout of Abf2 and knockdown of TFAM

4 decrease mtDNA (Diffley and Stillman, 1991; Megraw and Chae, 1993; Larsson et al., 1998;

5 Zelenaya-Troitskaya et al., 1998; Goto et al., 2001; Kanki et al., 2004). Abf2 also functions in

6 recombination of mtDNA (MacAlpine et al., 1998). Moreover, TFAM is involved in the

7 transcription of mtDNA (Parisi and Clayton, 1991; McCulloch and Shadel, 2003) and possibly

8 also in repairing mtDNA (Yoshida et al., 2003).

9 In the nucleus of the cell, various architectural proteins, including core and linker histones

10 and HMG proteins, are involved in structural features of the chromosome (Khorasanizadeh,

11 2004). In bacteria, the nucleoid is also organized not only by the histone-like protein called HU

12 but also by other architectural proteins including IHF, FIS, H-NS (Schmid, 1990). Recently, in

13 mt-nucleoids, more than 50 kinds of protein associated with mt-nucleoids, other than HMG

14 proteins, were identified in several species using mass spectrometry (Kaufman et al., 2000;

15 Chen et al., 2005; Wang and Bogenhagen, 2006; Bogenhagen et al., 2008). Many of them were

16 involved in mtDNA maintenance, including mitochondrial DNA polymerase (Foury, 1989),

17 mitochondrial RNA polymerase (Greanleaf et al., 1986), DNA helicase (Foury and Lahaye, 18 1987), mitochondrial single-stranded DNA-binding protein (Van Dyck et al., 1992), heat shock

19 proteins (Kaufman et al., 2000), aconitase (Chen et al., 2005), subunits of $\alpha$-ketoglutarate 20 dehydrogenase (Kaufman et al., 2000), prohibitin (Berger an Yaffe, 1998), acetohydroxyacid 21 reductase (Zelenaya-Troitskaya et al. 1995), and Mgm101 (Chen et al., 1993). However, except

22 for mitochondrial HMG and kinetoplast H1-like proteins, no architectural proteins involved in 23 the packaging of entire mtDNA have yet been identified.

24 In this study, we searched for a new mtDNA-packaging protein that organizes the whole 25 mt-nucleoid using a true slime mold, Physarum polycephalum. P. polycephalum has a simple 
1 and extraordinarily large rod-shaped mt-nucleoid (Kuroiwa, 1974). We previously established a

2 method to isolate highly purified mt-nucleoids from $P$. polycephalum that retain the same

3 structure and gene expression level as found in vivo (Suzuki et al., 1982; Sasaki et al., 1998).

4 Isolated mt-nucleoids consist of more than 70 proteins. Among these proteins, Glom was

5 identified as the most abundant basic protein, and in vivo constitutes one-fifth of the total

6 protein amount of mt-nucleoids (Sasaki et al., 2003). Glom possesses two HMG boxes, like

7 Abf2 and TFAM, and a lysine-rich region. It has high DNA-binding and DNA-agglomeration

8 ability. Glom was named as a protein inducing agglomeration of mitochondrial chromosomes.

9 Glom has polyproline tracts in the lysine-rich region, which are required for intense

10 condensation without suppressing DNA function. When isolated mt-nucleoids are

11 disassembled by a gradual increase in concentration of $\mathrm{NaCl}$ in buffer, several proteins are

12 released from the mt-nucleoids with Glom, correlating with dispersion of the nucleoid structure

13 (Sasaki et al., 2003). This suggests the possibility that these proteins might also be involved in

14 DNA packaging.

15 Here, we report a second mtDNA-packaging protein, Glom2, which organizes the entire mt-nucleoid together with Glom. Moreover, we report a new down-regulation method using 17 morpholino antisense oligos (MOs) in P. polycephalum. We suggest coordination of the two 18 mtDNA-packaging proteins in the organization and function of mtDNA.

\section{Materials and Methods}

\subsection{Strains and culture methods}

22 Microplasmodia of $P$. polycephalum, Colonia isogenic strain KM182 $\times$ KM187, were used to 23 isolate mitochondria for microinjection of MOs. Microplasmodia were cultured in 24 semi-defined liquid medium as described by Daniel and Baldwin (1964) at $23^{\circ} \mathrm{C}$. Cultures at the 25 middle exponential phase were used in the study. For microinjection of MOs, macroplasmodia 
1 (cultured in liquid medium) were collected by brief centrifugation, and then the $150 \mu 1$ of 2 pelletable material was spotted on MEA plates ( $1 \%$ malt extract, $0.17 \%$ mycological peptone,

$3 \quad 1.5 \%$ bacto-agar, and $2.5 \mu \mathrm{g} / \mathrm{ml}$ hemin) (Kawano et al., 1987) and cultured at $23^{\circ} \mathrm{C}$ in the dark.

4 Twenty-four hours later, macroplasmodia were fused into one plasmodium and used for 5 injection.

6 Myxamoebae of $P$. polycephalum, Colonia isogenic strain KM182, were used for 7 immunolocalization analysis. Myxamoebae were cultured on PGY plates (Ohta et al., 1993) 8 with live bacteria (Klebsiella aerogenes) as food at $23^{\circ} \mathrm{C}$.

\subsection{Preparation of mt-nucleoids}

11 Mitochondria and mt-nucleoids were isolated from microplasmodia of $P$. polycephalum as described in Sasaki et al. (1998). In this study, we developed a method for isolating mt-nucleoid

13 to remove the slight amount of remaining mitochondrial membrane. At first, we isolated the 14 mt-nucleoid as described in a previous report (Sasaki et al., 1998): the isolated mt-nucleoids 15 were resuspended in NE1-S buffer [0.5 M sucrose, $20 \mathrm{mM}$ Tris-HCl (pH7.7), $1 \mathrm{mM}$ EDTA (pH7.5), $7 \mathrm{mM}$ 2-mercaptoethanol, $0.4 \mathrm{mM}$ spermidine, and $0.4 \mathrm{mM}$ phenylmethylsulfonyl

17 fluoride $(\mathrm{PMSF})]$ to a concentration of $2 \mu \mathrm{g} / \mu \mathrm{l}$. The isolated mt-nucleoids were treated with $0.5 \%$ Nonidet P-40 (NP-40) for $1 \mathrm{~min}$ and centrifuged at $18,500 \times g$ for $10 \mathrm{~min}$. The sedimented 19 mt-nucleoids were washed twice, resuspended in NE1-S buffer, and stored on ice until use.

\subsection{In vitro disassembly of mt-nucleoids by NaCl or DNase}

22 The isolated mt-nucleoids $(8 \mu \mathrm{g})$ were suspended in NE1-S buffer to a concentration of 0.8 $23 \mu \mathrm{g} / \mu \mathrm{l}$. For disassembly of the mt-nucleoid by $\mathrm{NaCl}$, an equal volume of $\mathrm{NE} 1-\mathrm{S}$ buffer 24 containing $\mathrm{NaCl}$ at twice the final concentration was added to the suspension and incubated at $2525^{\circ} \mathrm{C}$ for $3 \mathrm{~h}$. For disassembly of mt-nucleoids by DNase I, DNase was added in NE1-S buffer 
1 contained $10 \mathrm{mM} \mathrm{MgSO}_{4}$ at a final concentration of $0.01 \mathrm{mg} / \mathrm{ml}$ and incubated at $25^{\circ} \mathrm{C}$ for $2 \mathrm{~h}$.

2 Each disassembled mt-nucleoid fraction was centrifuged at $18,500 \times g$ for $20 \mathrm{~min}$ at $4^{\circ} \mathrm{C}$. The

3 pelletable fraction and supernatant fraction were precipitated with tricarboxylic acid (TCA) and

4 subjected to sodium dodecyl sulfate-polyacrylamide gel electrophoresis (SDS-PAGE).

5

\section{2.4. DNA-cellulose column chromatography}

7 Mt-nucleoids $(80 \mu \mathrm{g})$ were incubated for $2 \mathrm{~h}$ at $25^{\circ} \mathrm{C}$ in high salt buffer $[1 \mathrm{M} \mathrm{NaCl}, 100 \mathrm{mM}$

8 Tris- $\mathrm{HCl}$ (pH7.0), $1 \mathrm{mM}$ EDTA, $10 \mathrm{mM}$ mercaptoethanol] to extract DNA-associated proteins.

9 The extracted fraction was centrifuged at $18,500 \times g$ for $20 \mathrm{~min}$. The supernatant was dialyzed 10 with equilibration buffer [50 mM NaCl, $100 \mathrm{mM}$ Tris- $\mathrm{HCl}$ (pH7.0), $1 \mathrm{mM}$ EDTA, $10 \mathrm{mM}$ 11 mercaptoethanol], and adsorbed to the native DNA-cellulose column (GE Healthcare, 12 Milwaukee, WI). Proteins were eluted with various concentration of $\mathrm{NaCl}$ buffer [0.1, 0.2, 0.3 , $130.4,1.0$, or $2.0 \mathrm{M} \mathrm{NaCl}, 10 \mathrm{mM}$ Tris- $\mathrm{HCl}$ (pH7.7), $1 \mathrm{mM}$ EDTA, $10 \mathrm{mM}$ mercaptoethanol]. The 14 eluted fractions precipitated with TCA were subjected to SDS-PAGE.

15

\subsection{Cloning of Pmn56 cDNA}

The isolated mt-nucleoids were electroblotted onto a polyvinylidene fluoride (PVDF) membrane, and bands of $56 \mathrm{kDa}$ were sequenced from the $\mathrm{N}$-terminus using a protein sequencing system (model procise, 494/492cLC); the following 22-amino acid sequence was obtained: TTETEVAFPVEAPNAYPTRTSD. To obtain internal peptide sequences, the electroblotted Pmn56 was digested with Achromobacter protease I in 0.1\% SDS, 1 mM EDTA, and $100 \mathrm{mM}$ Tris- $\mathrm{HCl}(\mathrm{pH} 9.0)$ at $37^{\circ} \mathrm{C}$ overnight. The digested peptides were separated by reverse-phase high-performance liquid chromatography (HPLC) with a linear gradient of acetonitrile from $0 \%$ to $50 \%$ in $0.085 \%$ or $0.075 \%$ TFA. Two peptides were sequenced using a protein sequencer, and the following 12 and 25 amino acid sequences were obtained: 
1 EIRAFTTTSQPK and FGLQIAIEDAQAPVPDLEEQAIPQQ.

2 Using cDNA of $P$. polycephalum, reverse transcription (RT)-PCR was performed with four 3 degenerate primers based on the amino acid sequences obtained; first PCR: 4 5'-GARACIGARGTIGCTTYCC-3' (Pmn56F1) and 5'-GTIGTRAAIGCICKDATYTC-3' 5 (Pmn56R1) and second PCR: (Pmn56F1) and 5'-GARACICARGCICCIGU-3' (Pmn56R2).

6 The resulting PCR fragment was cloned and sequenced. For cloning of the full-length Pmn56, 7 5'- and 3'-rapid amplification of cDNA ends (RACE) PCR analyses were carried out 8 (GeneRacer Kit, Invitrogen). For 5'-RACE, we used 5'-GCCAATGCCCAAATCCTTGCAG-3' 9 (Pmn56-5race1) and GeneRacer 5'-primer in the first PCR, and 10 5'-GCTCCAGGGCCAAATGCACGATT-3' (Pmn56-5race2) and GeneRacer 5'-nested primer 11 in the second PCR. For 3'-RACE, we used 5'-GCCTTTAGAGACTGGTGTTG-3' 12 (Pmn56-3race1) and GeneRacer 3'-primer in the first PCR, and 13 5'-ATTTGGCCTCCAGATTGCCA -3' (Pmn56-3race2) and GeneRacer 3'-nested primer in the 14 second PCR. The Genbank accession number of Glom2/Pmn56 is AB537161.

\subsection{Phylogenetic analysis}

17 Phylogenetic analysis (neighbor joining) was done using the default setting of NJPlot (Perrière, 18 et al., 1996). GenBank Accession Numbers for sequences for phylogenetic analysis are 19 XP_642651 (Dictyostelium discoideum), XP_002111538 (Trichoplax adhaerens), NP_596277 20 (Schizosaccharomyces pombe), XP_572928 (Cryptococcus neoformans), XP_755290 21 (Aspergillus fumigatus), CAA48502 (Saccharomyces cerevisiae), XP_002416920 (Candida 22 dubliniensis), XP_001623521 (Nematostella vectensis), XP_002111538 (Trichoplax 23 adhaerens), and CAJ75143 (Kuenenia stuttgartiensis).

\subsection{Antibody preparation}


1 The C-terminal half of Pmn56 (amino acids 247-458) was expressed in Escherichia coli BL21

2 (DE3) CodonPlus (Novagen, Darmstadt, Germany) as a polyhistidine (His)-tagged protein

3 using vector pET-21a (Novagen). This protein was purified using Ni-chelating affinity column

4 chromatography (HisTrap FF column; GE Healthcare) and then used to raise polyclonal rabbit

5 antisera. An anti-Pmn56c antibody was purified from serum by Protein G affinity

6 chromatography (MABTrap Kit; GE Healthcare).

7

$8 \quad$ 2.8. Immunoblot and immunofluorescence

9 For immunoblotting analysis of cell fractionation, $1 \mu \mathrm{g}$ of each fraction (cell, mitochondria, 10 mitochondrial sup, mt-nucleoid) was electrophoresed and blotted onto PVDF membranes 11 (Immobilon-P; Millipore, Billerica, MA). The primary antibody was anti-Pmn56C at a dilution 12 of $1: 20,000(\mathrm{v} / \mathrm{v})$ in gelatin blocking buffer [1\% gelatin in Tris-buffered saline (TBS) 13 containing $0.05 \%$ Tween-20], and the secondary antibody was peroxidase-conjugated goat 14 anti-rabbit IgG (KPL) at a dilution of 1:20,000 (v/v) in gelatin blocking buffer. For 15 immunoblotting analysis of the MO sample, $12 \mu \mathrm{g}$ of each total cell extract was electrophoresed and blotted onto PVDF membranes. The primary antibodies were anti-Glom and anti-ANT, 17 diluted 1:5000 (v/v) in gelatin blocking buffer, and the secondary antibody was 18 peroxidase-conjugated goat anti-rabbit IgG at a dilution of 1:20,000 (v/v) in gelatin blocking 19 buffer.

20 For immunofluorescence staining, amoebae cells were fixed onto a coverslip with $3.7 \%$ 21 formaldehyde in $25 \mathrm{mM}$ potassium phosphate buffer (KPB) for $20 \mathrm{~min}$, and then permeabilized 22 with $0.1 \%$ Triton $\mathrm{X}-100$ in distilled water for $12 \mathrm{~h}$ at $4^{\circ} \mathrm{C}$. The amoebae cells were treated for 1 $23 \mathrm{~h}$ with the anti-Pmn56C antibody at a dilution of 1:500 (v/v) in bovine serum albumin (BSA) 24 blocking buffer (5\% BSA in KPB). The secondary antibody was Alexa Fluor 488-conjugated 25 anti-rabbit goat IgG (Molecular Probes, Eugene, OR) at a dilution of 1:500 (v/v) in BSA 
1 blocking buffer.

2

\section{$3 \quad$ 2.9. Purification of recombinant proteins}

4 Full-length mature Pmn56 (amino acids 44-458) was expressed as a His-tagged protein using 5 vector pET-28 (Novagen) in E. coli BL21 (DE3) CodonPlus. This expressed protein was

6 purified using a Ni-chelating affinity chromatography column, and then refolded with a 6-0 M 7 urea gradient and dialyzed against buffer A $[50 \mathrm{mM}$ Tris- $\mathrm{HCl}(\mathrm{pH} 7.5), 150 \mathrm{mM} \mathrm{NaCl}, 1 \mathrm{mM}$

8 EDTA, $1 \mathrm{mM}$ dithiothreitol (DTT)]. The recombinant Glom was expressed and purified as 9 described by Sasaki et al. (2003).

\subsection{DNA mobility shift assay}

Purified full-length mature of Pmn56 (Pmn56m) was analyzed for its DNA-binding activity

13 using electrophoretic mobility shift assays with XbaI-digested mtDNA of P. polycephalum.

14 Two microliters of purified Pmn56m or BSA in buffer A was added to $8 \mu 1$ of reaction buffer [50 $15 \mathrm{mM}$ Tris- $\mathrm{HCl}(\mathrm{pH} 7.0)]$ containing $200 \mathrm{ng}$ of DNA and incubated at $26^{\circ} \mathrm{C}$ for $1 \mathrm{~h}$. The reaction mixtures were applied to $1 \%$ agarose gels in TAE buffer $[40 \mathrm{mM}$ Tris-acetate (pH8.0) and 2

17 mM EDTA]. After electrophoresis, gels were stained with ethidium bromide.

\subsection{RNA mobility shift assay}

20 Purified full-length mature of Pmn56 (Pmn56m) was analyzed for its RNA-binding activity 21 using electrophoretic mobility shift assays with total mitochondrial RNA of P. polycephalum.

22 Total mitochondrial RNA was extracted with the RNeasy Plant Mini Kit (Qiagen) from isolated 23 mitochondria. Each $2 \mu 1$ of purified Pmn56m, purified Glom, Ribonuclease (50 ng), or BSA (2 $24 \mu \mathrm{g})$ in buffer A was added to $8 \mu \mathrm{l}$ of reaction buffer [50 mM Tris- $\mathrm{HCl}(\mathrm{pH} 7.0)]$ containing 200 25 ng of RNA and incubated at $26^{\circ} \mathrm{C}$ for $1 \mathrm{~h}$. The reaction mixtures were applied to $1 \%$ agarose 
1 gels in TAE buffer. After electrophoresis, gels were stained with ethidium bromide.

2

\section{2.12. DNA condensation assay}

4 Two microliters distilled water containing $450 \mathrm{ng}$ mtDNA (not digested) and $1.8 \mu \mathrm{l}$ each of 5 purified Pmn56m, Glom, or BSA in buffer A were added to $6.6 \mu 1$ of reaction buffer [50 mM

6 Tris- $\mathrm{HCl}(\mathrm{pH} 7.5)]$ and then incubated at $26^{\circ} \mathrm{C}$ for $1 \mathrm{~h}$. The reaction mixtures were examined by 7 4',6-diamidino-2-phenyl-indole (DAPI) fluorescence microscopy.

\subsection{Microinjection of MOs into the plasmodium}

10 MOs conjugated fluorescein 5-isothiocyanate (FITC) at the 3'-end were obtained from Gene

11 Tools, LLC (Philomath, OR). The sequences of MOs against Glom or Glom2 mRNA located 12 near the translation initiation site were as follows:

14 ATG-TAC-ACT-AGG-GTG-GCC-AGG-GTT-T (Glom2). As negative controls, inverted 15 oligos (Inv.) and without injection (W/O) were used. After dissolution in distilled water to a concentration of $1 \mathrm{mM}$, each $1.5 \mu \mathrm{l}$ of $\mathrm{MO}$ was mixed or diluted to $3.0 \mu 1$ and injected with a glass needle into macroplasmodia on MEA plates. Injections were applied to large veins at three to five different spots. The glass needle, with an outer diameter at the tip of 8-10 $\mu \mathrm{m}$, was made by pulling glass capillaries (GD-1; Narishige, Tokyo, Japan) with PC-10 micropipette pullers (Narishige) and then trimming to a needlepoint with the side of a glass slide. on a fresh agar plate as an inoculum. At 5.5 days after the first injection, the plasmodium was

24 re-injected with MOs. Then 12 days after the first injection, a part of the plasmodium was scraped from the agar plate and analyzed. In a single experiment, each MO was injected to one 
1 multinucleate cell. We repeated this experiment 2-5 times independently and respectively.

2

\section{$3 \quad$ 2.14. Microscopic observations}

4 To observe the mitochondria and mt-nucleoid, cells were fixed with $0.2 \%$ glutaraldehyde in 12 $5 \mathrm{mM} \mathrm{KPB}(\mathrm{pH} 7.0)$ containing $0.1 \%$ Triton $\mathrm{X}-100$ and $0.25 \%$ Tween 20 , and DNA was then 6 stained with DAPI. Samples were observed with a BX51 microscope (Olympus, Tokyo, Japan).

7 Images processing and analysis were performed with the following software: Adobe Photoshop

8 7.0.1 (Adobe systems, CA, USA) and ImageJ (http://rsb.info.nih.gov/ij/).

9

\subsection{Real-time PCR}

We applied real-time PCR to detect the mtDNA copy number and mitochondrial RNA accumulation levels. The real-time PCR used the StepOnePlus Real-Time PCR Detection System (Applied Biosystems, Foster City, CA) with the SYBR Green I detection method. Each real-time PCR (20 $\mu$ l total volume) contained $9 \mu 1$ of template genomic DNA (50 ng) or cDNA diluted in distilled water, $10 \mu 1$ of $2 \times$ Power SYBR Green PCR Master Mix (Applied Biosystems), and $1 \mu 1$ of each forward and reverse primer. Samples were denatured by heating at $95^{\circ} \mathrm{C}$ for $10 \mathrm{~min}$, followed by 42 cycles of amplification and quantification $\left(95^{\circ} \mathrm{C}\right.$ for $15 \mathrm{~s}$ and $60^{\circ} \mathrm{C}$ for $\left.1 \mathrm{~min}\right)$. Each measurement was repeated at least three times and normalized in each experiment against the control.

For mtDNA copy number analysis, total cellular DNA from cells was extracted using the Plant DNeasy Mini Kit (Qiagen, Hilden, Germany) according to the manufacturer's instructions. As previously described, we compared the relative amounts of mtDNA and nuclear DNA copy number. mtDNA amplicons were generated from the mitochondrial rRNA segment using mtDNA primers (rRNA: 5'-CACACTAGCTAAGGACCGCAATAA-3' and 5'-CGTGAGCTGTAACGCTTTCTTTAA-3', fragment length $110 \mathrm{bp}$ ). The nuclear amplicon 
1 was generated by amplifying the Glom segment, which occurs in a single copy, using nuclear 2 DNA primers (Glom: 5'-TGTCAGCCTTTTCCATCTTCGT-3' and

3 5'-TGCTTGGACAATTGCTTCATG-3', fragment length $100 \mathrm{bp}$ ). The threshold cycle number

4 (Ct) values for Glom and mtDNA were determined for each individual quantitative PCR run.

5 For mitochondrial RNA accumulation analysis, total RNA was extracted with the RNeasy Plant

6 Mini Kit (Qiagen) with the RNase-Free DNase Set (Qiagen). Reverse transcription was

7 performed with random primers (6mer) and SuperScript III Reverse Transcriptase (Invitrogen,

8 Carlsbad, CA). The primers for GAPDH as an internal standard were

9 5'-TGGCTAAGATCATCCACGAGAAG-3' and 5'-TGCCAGAGGGACCATCTACAG-3'

10 (fragment length 102 bp). In P. polycephalum, nearly all mitochondrial transcripts require a

11 large range of RNA editing activity (Byrne et al., 2007). The primers for three genes on the

12 mitochondrial genome were designed with reference to Gott et al. (1993) and Takano et al.

13 (2001). The primers for cox 1 were 5'-TGGGTTTTATAGTGTGGGCTCAT-3' and

14 5'-CGTTGGCACAGCAATATCATAGTAG-3' (fragment length $101 \mathrm{bp}$ ). The primers for nad6

15 were 5'-TACATTTACGCTCATACACGC-3' and 5'-GGTATCGCTAAATAAAAAAGTC-3'

16 (fragment length $104 \mathrm{bp}$ ), and for nad7 were 5'-TCATAAAACGGTCATAACAATC-3' and

17 5'-CTGGTGTTATGGTTCGAGGTAG-3' (fragment length 129 bp).

\subsection{Northern blot analysis}

20 Total RNA was extracted with the RNeasy Plant Mini Kit (Qiagen) with the RNase-Free DNase

21 Set (Qiagen). For Northern analysis, RNA samples (2, 6, $3.6 \mu \mathrm{g}$ for cox1, nad6, nad7

22 respectively) were separated on $1.4 \%$ agarose gels in $10 \mathrm{mM}$ sodium phosphate $(\mathrm{pH} 7.0)$ and

23 transferred to Hybond-N+ membranes (GE Healthcare) by capillary elution with $20 \times$ SSC

24 buffer $(3 \mathrm{M} \mathrm{NaCl}, 0.3 \mathrm{M}$ sodium citrate, $\mathrm{pH}$ 7.0). Membranes were hybridized with

25 gene-specific probes and detected using the AlkPhos Direct Labelling and Detection System 
1 with CDP-Star (GE Healthcare). The primers for cox1 probe were 2 5'-ATACCTTCGCAGATCGTTGG-3' and 5'-CCTGCTAAGACAGGCAGTGA-3'. The 3 primers for nad6 probe were 5'-TGCTTTTAAGCTTTATATTTTTCTCC-3' and 4 5'-AtAGCAGTtGTTTTATTATATCCGACA-3'. The primers for nad7 probe were 5 5'-GGCTTtTGAAGAGCGAGAAA-3' and 5'-TCCTTTTGGAGCTTCGACAC-3'.

6 Hybridization signals were visualized on a luminescent image analyzer (LAS4000mini, GE

7 Healthcare). The regions hybridized with DNA probes in mRNA were 679 base (cox1), 487

8 base (nad6), and 610 base (nad7) respectively.

9

10

11 


\section{3. Results}

\section{3.1. Identification of $56-\mathrm{kDa}$ protein from isolated mt-nucleoids as candidate}

3 mtDNA-packaging protein

4 The mt-nucleoid of $P$. polycephalum consists of more than 70 proteins (Sasaki et al., 2003). To

5 search for mtDNA-binding proteins required for the packaging of mtDNA, we compared the

6 results of three parallel experiments, namely, disassembly of mt-nucleoids by $\mathrm{NaCl}$ treatment,

7 disassembly of mt-nucleoids by DNase I treatment, and affinity chromatography of

8 mt-nucleoid proteins using a DNA-cellulose column. Candidate mtDNA packaging proteins

9 were expected from all three experiments.

10 First, we investigated which proteins were released from the mtDNA along with Glom on 11 disassembly of the isolated mt-nucleoid structure. mt-nucleoids were treated with $\mathrm{NaCl}$ of 12 increasing ionic strength to induce their disassembly. These were centrifuged and the 13 supernatant and pellet fractions analyzed by SDS-PAGE (Fig. 1A). The condensed nucleoid 14 structure began to disassemble at $0.2 \mathrm{M} \mathrm{NaCl}$, as previously reported (Sasaki et al., 2003). At $150.2 \mathrm{M} \mathrm{NaCl}$, proteins of 38-, 56-, 60-, 68-, 70-, 90-, 130-, and 170-kDa began to be released into the supernatant fraction and were almost completely released at $0.5 \mathrm{M} \mathrm{NaCl}$, together with

17 Glom (Fig. 1A and Table 1). These proteins are possibly involved in organization of the 18 mt-nucleoid structure.

19 Second, we investigated which proteins were released from mt-nucleoids with Glom on 20 disassembly of its structure with DNase I, which induces partial digestion of mtDNA. When 21 mt-nucleoids were treated with $0.01 \mathrm{mg} / \mathrm{ml}$ DNase I at $25^{\circ} \mathrm{C}$ for $2 \mathrm{~h}$, DAPI staining showed that 22 the rod-shaped structure was dispersed, as seen with the $\mathrm{NaCl}$ treatment (supplementary 23 information, Fig. S1). The extract was centrifuged and the supernatant and pellet fractions 24 analyzed by SDS-PAGE (Fig. 1B). DNA-binding proteins are predicted not to be released to the 25 supernatant without DNase I treatment (-), but will be released after DNase treatment $(+)$. As 
1 well as Glom, proteins of 20-, 31-, 34-, 38-, 40-, 40.5-, 52-, 56-, and 90-kDa were released to

2 the supernatant after the DNase I treatment (Fig. 1B and Table 1). These proteins are the second

3 candidate involved in organization of the mt-nucleoid structure. In these proteins, 34-kDa

4 protein (Pmn34) was identified as a protein which has an exonuclease motif and localizes in the

5 mt-nucleoid periphery (Itoh et al., 2009).

6 Third, a DNA-cellulose chromatography was used to identify candidate proteins that bind to

7 DNA. Mt-nucleoid proteins were prepared using a $1.0 \mathrm{M} \mathrm{NaCl}$ treatment and were adsorbed

8 onto a native DNA-cellulose column. Proteins bound to the column were eluted with various

9 concentrations of $\mathrm{NaCl}$. SDS-PAGE analysis showed that 34-, 38-, 56-, 70-, and 95-kDa

10 proteins were mainly eluted with $0.3 \mathrm{M} \mathrm{NaCl}$ and that a 56-kDa protein was mainly eluted with

$110.4 \mathrm{M} \mathrm{NaCl}$, together with Glom (Fig. 1C and Table 1). Glom and the 56-kDa protein were

12 suggested to bind more strongly to DNA than the other candidate proteins because they

13 remained bound to the DNA column even at higher $\mathrm{NaCl}$ concentrations. As summarized in

14 Table 1, a 56-kDa protein was found in all experiments and had similar properties to Glom. This

15 protein is one of the most abundant proteins of the mt-nucleoid (Fig. 1A-1C). Thus, in further

16 analysis, we focused on the 56-kDa protein, hereafter called Pmn56 ( $\underline{P}$. polycephalum

17 mitochondrial nucleoid protein $\underline{56})$.

3.2. Primary structure of Pmn56 has an N-terminal Mgm101 half and a unique C-terminal

half

21 Partial amino acid sequences of the N-terminal and internal structure of Pmn56 were

22 determined using the Edman degradation method. After a partial coding sequence of cDNA was

23 determined by degenerate PCR analysis, the sequence of the full-length cDNA was determined

24 by 3'- and 5'-RACE analysis. The primary sequence of Pmn56 suggests that it encoded a 25 positively charged protein of 458 amino acids. The mature amino terminus of the protein is 
1 located 44 residues after the putative initiation codon. Therefore, the first 43 amino acids are

2 assumed to be a mitochondrial transit peptide resulting in a mature protein of 415 amino acids.

3 This is consistent with Pmn56 being encoded by the nuclear genome, as the mitochondrial

4 genome does not contain the Pmn56 gene (Takano et al., 2001). The molecular mass of mature

5 Pmn56 was estimated at 45,860. The difference from the apparent molecular mass, 56-kDa,

6 might be due to a positive charge in mature Pmn56 (isoelectric point: 8.15).

7 BLAST search analysis revealed that Pmn56 has an Mgm101 domain in the N-terminal half

8 (amino acids 70-239), which has been identified as a mitochondrial nucleoid protein involved

9 in mtDNA maintenance (Chen et al., 1993). This domain is found in a variety of species,

10 including protozoa, fungi, and animals (Fig. 2A-2C). The C-terminal half of Pmn56 (amino

11 acids 240-458) showed no sequence homology with other known proteins, except for three

12 polyproline tracts, which are present in the lysine-rich, N-terminal half of Glom (Sasaki et al.,

13 2003). Both the C-terminal half and N-terminal half of Pmn56 are rich in basic amino acids. No

14 specific DNA-binding motif was found.

15

\subsection{Pmn56 is localized to the entire mt-nucleoid}

17 We raised a polyclonal antibody against the C-terminal half of Pmn56 expressed in E. coli. To 18 examine the intracellular localization of Pmn56, we performed Western blotting using various

19 fractionations of the cell: total cell extract, mitochondria, mitochondrial-sup (matrix and 20 membrane), and mt-nucleoids. Pmn56 was specifically recognized by the antibody and was 21 concentrated in the mt-nucleoid fraction (Fig. 3A), but was scarcely detected in the 22 mitochondrial-sup fraction. We next performed immunostaining to visualize Pmn56 in the 23 mt-nucleoid of amoeba cells (Fig. 3B). We found that Pmn56 was localized to all mt-nucleoids 24 but not to the nucleus. Moreover, Pmn56 was localized uniformly to the entire mt-nucleoid. By 25 SDS-PAGE and Western blotting analysis, we investigated the physiological concentration of 
1 Pmn56 and Glom in the mt-nucleoid. Both results showed that $5 \mu \mathrm{g}$ of mt-nucleoid contained

2 approximately $0.25 \mu \mathrm{g}$ of Pmn56m and $1 \mu \mathrm{g}$ of Glom (data not shown). Because it has been

3 reported that $5 \mu \mathrm{g}$ of mt-nucleoid contains $450 \mathrm{ng}$ of mtDNA in vivo (Sasaki et al., 2003), it was

4 calculated that the mt-nucleoid contained about $0.56 \mu \mathrm{g}$ of Pmn56m per $\mu \mathrm{g}$ of mtDNA.

5

$6 \quad$ 3.4. Pmn56 has ability for mtDNA and mitochondrial RNA binding

7 To determine whether Pmn56 directly binds to mtDNA and mitochondrial RNA, we performed

8 DNA and RNA mobility shift assay using a recombinant protein of Pmn56m, a mature form

9 lacking the transit peptide (Fig. 4A). The purity of the recombinant proteins was checked by

10 SDS-PAGE (Fig. 4B) Isolated mtDNA of P. polycephalum was digested by XbaI and mixed

11 with Pmn56m (Fig. 4C). Electrophoresis of the protein-DNA mixture showed that mtDNA was trapped in wells as the concentration of Pmn56m increased. At $4 \mu \mathrm{M}$ of Pmn56m, all fragments of $200 \mathrm{ng}$ mtDNA were completely trapped in these wells. The possibility exists that Pmn56m-bound DNA could not enter the gel. This result suggests that Pmn56m was directly bound to mtDNA without sequence specificity and induced DNA condensation. No aggregation of Pmn56m was observed at $4 \mu \mathrm{M}$ without DNA. This characteristic of Pmn56 is different from that of Glom, which causes shifts in mtDNA mobility but not trapping of mtDNA in wells of the gel (Sasaki et al., 2003). Isolated mitochondrial RNA of $P$. polycephalum was mixed with Pmn56m or Glom, and analyzed by agarose gel electrophoresis (Fig. 4D). The mitochondrial RNA was not shifted when it was incubated with a high amount of BSA, which was used as a negative control. All mitochondrial RNA was clearly shifted at high amount of Pmn56m and Glom. The revel of RNA fragments shift with $2 \mu \mathrm{M}$ of Pmn56m was equivalent to that with $1.5 \mu \mathrm{M}$ of Glom, indicating that Pmn56m and Glom could bind to all mitochondrial RNA, and the ability of RNA binding of Glom is much higher than that of Pmn56m. 


\section{$1 \quad$ 3.5. Pmn56 is a mtDNA-packaging protein with an ability for mtDNA condensation}

2 To evaluate the DNA condensation ability of Pmn56m using isolated mt-nucleoids, we

3 performed the in vitro reassembly assay as described by Sasaki et al. (2003). The isolated

4 mt-nucleoids were disassembled by treatment with $0.3 \mathrm{M} \mathrm{NaCl}$. This disassembly process was

5 reversible: subsequent dialysis of the high-salt treated sample induced reassembly of the

6 mt-nucleoids into a condensed, rod-shaped form (Fig. 4Ec). Thus, the factors required for DNA

7 condensation can re-associate with mtDNA to reassemble mt-nucleoid structure upon dilution

8 from high-salt solution. Conversely, when the high-salt sample was depleted by centrifugation

9 and the supernatant fraction removed before dialysis, reassembly was severely inhibited (Fig.

10 4Ed). Consistent with a previous work, the addition of purified Glom into the $0.3 \mathrm{M} \mathrm{NaCl}$

11 supernatant-depleted fraction at physiological protein/DNA ratio induced the reassembly of the

12 mt-nucleoids (Fig. 4Ee, Sasaki et al., 2003). The addition of purified Pmn56m at physiological

13 protein/DNA ratio also induced the reassembly of the mt-nucleoids like Glom (Fig. 4Ef). As the

14 concentration of Pmn56m increased, the condensed level also increased (Fig. 4Ef-4Eh). These

15 results demonstrated that Pmn56 is able to packaging the mt-nucleoid into a highly condensed

16 state like Glom in vitro. Therefore, we named Pmn56 as Glom2 (a protein inducing

17 agglomeration of mitochondrial chromosome 2).

18 Then we analyzed the DNA condensation ability of Glom2 using isolated mtDNA. Isolated

19 mtDNA was incubated with various amounts of purified Glom2 and/or Glom, and observed

20 after DAPI staining (Fig. 4F). When $450 \mathrm{ng}$ of mtDNA was incubated with $0.25 \mu \mathrm{g}$ of Glom2 at

21 physiological concentration $(0.5 \mu \mathrm{M})$, Glom2 induced slight DNA condensation after DAPI

22 staining (Fig. 4Fa). As the concentration of Glom2 increased, the condensed level also

23 increased (Fig. 4Fa-4Fc). Although we did not find DNA condensation when 450 ng of mtDNA

24 was added to $0.2 \mu \mathrm{g}$ of Glom $(0.5 \mu \mathrm{M})$ (Fig. $4 \mathrm{Fd})$, DNA condensation was promoted by more

25 than $1 \mu \mathrm{g}$ of Glom at physiological concentration $(2.5 \mu \mathrm{M})$ (Fig. 4Fe and 4Ff). This means that 
1 Glom2 could condense DNA at lower concentration $(0.5 \mu \mathrm{M})$ than Glom, implying that Glom2

2 has higher condensation activity than Glom. Note that mixing Glom2 and Glom together at

3 physiological concentrations $(0.5 \mu \mathrm{M}$ and $2.5 \mu \mathrm{M}$, respectively) considerably enhanced the

4 condensation activity. This was not due to an increase in the amount of proteins ( $3 \mu \mathrm{M}$ in total)

5 because incubation with $3 \mu \mathrm{M}$ of Glom caused less condensation, which suggests that Glom2

6 and Glom work synergistically for condensation of mtDNA.

7

\section{3.6. Development of a down-regulation method for targeted genes using MOs}

9 To investigate the function of Glom2 in vivo, we developed a down-regulation technique in $P$.

10 polycephalum. Since plasmodium is a single multinucleate cell, materials injected into a part of

11 it can spread to the entire plasmodium. We first tried an RNAi method by injecting siRNA, as

12 described previously, in P. polycephalum (Haindl and Holler, 2005; Pinchai et al., 2006);

13 however, expression of the targeted genes did not sufficiently decrease in our system. Therefore,

14 we used MOs, which are nucleic acid analogs resistant to nucleases that are able to sustainably

15 inhibit the expression of targeted genes by blocking the access of other molecules for

16 translation and splicing in many organisms (Karkare and Bhatnagar, 2006). We designed MOs

17 against the translation initiation site of mRNA so that translation of targeted genes was inhibited.

18 When FITC-labeled MOs were injected into one of the main veins of the plasmodium, the

19 fluorescence of MOs spread to the periphery instantaneously and then gradually spread

20 throughout the entire cell within $2 \mathrm{~h}$ (Fig. 5A). We injected $3 \mu \mathrm{l}$ of MO into each cell, which is

21 less than $1 \%$ of the total cell volume.

22 We first tested a Glom2 MO to specifically down-regulate the Glom2 gene. The expression 23 of Glom 2 began to decline 1 day after injection, began to recover 7 days after injection, and 24 fully recovered to the original level 11 days after injection (supplementary information, Fig. S2).

25 Note that such a sequential analysis in a single cell was possible in P. polycephalum because we 
1 could collect part of a cell without killing it. For more continuous and severe down-regulation,

2 MO was re-injected to the plasmodium 5.5 days after the first injection (Fig. 5B). At 12 days

3 after the first injection, the expression of Glom2 was considerably reduced compared to

4 negative controls, i.e., W/O or Inv. cells (Fig. 5C). Expression of neither Glom nor ANT

5 (mitochondrial outer membrane protein; Wada et al., 2007) changed after the injection of

6 Glom2 MO. We repeated the experiments at least twice for each MO, and similar

7 down-regulation was seen in all experiments.

8 Specific down-regulation of Glom was also observed after injection of Glom MO. Moreover,

9 when we simultaneously injected MOs for both Glom and Glom2, their proteins were reduced

10 at the same time (Fig. 5C). We found defects in proliferation of injected cells (Fig. 5D). The

11 injection of Glom2 MO did not cause an apparent defect in the growth speed of cells, but we

12 detected a significant delay in the cell cycle when measured from days 12 to 15 after the first

13 injection. The time required for one nuclear division cycle from one $\mathrm{M}$ phase to the next was 17

$14 \mathrm{~h}$ in injected cells but $13 \mathrm{~h}$ in cells without injection. Moreover, the growth speed was severely

15 decreased by down-regulation of Glom or both Glom and Glom2. The apparent difference in

16 growth speed appeared from 4 days after injection, and the nuclear division cycle was

17 prolonged to more than $20 \mathrm{~h}$. In most cases, down-regulation of both Glom and Glom2

18 appeared to cause a severe defect in the growth speed of cells (Fig. 5D). We repeated

19 experiments more than five times for each MO, and a similar defect in growth speed was always

20 observed, suggesting a high success rate and reproducibility of our system. These results for

21 MO injection together suggest that Glom and Glom2 were both required for normal cell

22 proliferation.

24 3.7. Glom2 has different functions from Glom in the mt-nucleoid

25 We examined whether down-regulation of Glom and/or Glom2 caused changes in nucleoid 
1 structure (Fig. 6A and 6B). We could not find any change in the mt-nucleoid at 12 days after

2 injection of Glom2 MO. Down-regulation of Glom2 did not induce loss of mtDNA even after

3 more than 25 days after injection (approximately 50 cell divisions) in $P$. polycephalum.

4 However, in the case of injection of Glom MO, smaller or thinner mt-nucleoids were found at

512 days after injection that were not observed in cells without injection. Furthermore,

6 simultaneous down-regulation of both Glom and Glom2 led to the loss of the rod-shaped

7 structure of mt-nucleoids; most became smaller and completely round, with no difference in

8 length between the major and minor axes. Not only smaller but very large mt-nucleoids

9 emerged in this case. These results suggest that Glom, but not Glom2, is essential for

10 mt-nucleoid structure. Note that the fluorescence intensity of DAPI staining did not change in

11 these mt-nucleoids, suggesting that mtDNA was still packed in a condensed state.

12 We investigated whether down-regulation of Glom and Glom2 caused changes in the total

13 copy number mtDNA in the cell using real-time PCR (Fig. 6C). Consistent with observations

14 after DAPI staining (Fig. 6A), the copy number of mtDNA did not change significantly in cells

15 injected with Glom $2 \mathrm{MO}(P>0.05$, Student's $t$-test $)$ but decreased significantly in cells injected with Glom MO (33\% against W/O; $P<0.003$, Student's $t$-test $)$ or both Glom and Glom2 MOs

17 (5.5\% against W/O; $P<0.001$, Student's $t$-test $)$. The difference between Glom MO and both

18 Glom MOs was also significant $(P<0.001$, Student's $t$-test). These results suggest again the

19 primary role of Glom and synergistic role of Glom2 in the maintenance of mtDNA.

20 We then investigated whether down-regulation of Glom and Glom2 caused changes in the 21 transcript accumulation level of mtDNA by Northern blot analysis using probes for three genes 22 on the mitochondrial genome, namely cox1, nad6, and nad7 (Fig. 6D). These three genes are 23 localized to different loci on the mitochondrial genome (Takano et al., 2001; Gott et al., 2005).

24 We found that the transcript accumulation levels of cox 1 and nad7, but not nad6, decreased in 25 cells injected with Glom2 MO against that in W/O cells. On the other hand, all transcript 
1 accumulation of three genes decreased in cells injected with Glom MO or both Gloms MOs.

2 We next performed real-time RT-PCR to measure the transcript accumulation revel 3 quantitatively. We found that the transcripts level of cox 1 and nad7 decreased to $41.8 \%$ and $441.1 \%$, respectively, in Glom2 depressed cells against W/O cells (Fig. 6E). On the other hand, 5 the transcripts level of cox6 was maintained. The expression level of cox 1 and nad7 in cells 6 injected with Glom2 MO tended to decrease to a similar extent as with Glom MO, despite no 7 significant decrease in the copy number of mtDNA in the Glom2 depressed cells. We repeat the 8 experiments at least twice for each MO, and a similar change was seen in all experiments. Thus, 9 Glom2 is likely to play a different role from that of Glom in the mt-nucleoid. 


\section{4. Discussion}

2 The mtDNA of many organisms is packed by the major HMG-type mtDNA packaging proteins, 3 Abf2, TFAM, and Glom (Diffley and Stillman, 1992; Ghivizzani et al., 1994; Sasaki et al.,

4 2003). In this study, we identified a new Mgm101-type mtDNA packaging protein, Glom2,

5 which is involved in mt-nucleoid organization, genome maintenance, and gene expression.

6 Like major HMG-type mtDNA packaging proteins, Glom2 is localized to the entire

7 mt-nucleoid and directly bound to mtDNA with no sequence specificity. Although the amount

8 of Glom2 was smaller than that of Glom, Glom2 was abundant in the mt-nucleoid. Quantitative

9 analysis of Glom 2 revealed that it contained approximately $1 / 20$ of the total mt-nucleoid

10 proteins, meaning that one molecule of Glom2 exists per $100 \mathrm{bp}$ of mtDNA. Because Glom

11 binds to every $20 \mathrm{bp}$ of mtDNA (Sasaki et al., 2003), the molar ratio of Glom:Glom2 in the

12 mt-nucleoid is 5:1.

13 We previously showed that Glom induced reassembly of mt-nucleoids into a highly 14 condensed state in vitro (Sasaki et al., 2003). In these reassembled mt-nucleoids, 15 poly-beaded-like structures similar to non-treated mt-nucleoids were observed. In this study, we showed that not only Glom but also Glom2 had the ability for DNA condensation in vitro

17 (Fig. 4E, 4F). Although the DNA condensation ability of Glom2 appeared higher than that of 18 Glom, the condensed DNA from Glom2 at a physiological ratio (Fig. 4Fa) was much less than 19 that for Glom (Fig. 4Fe). These results suggest that Glom is more important for the architecture 20 of the mt-nucleoid than Glom2. Indeed down-regulation of Glom, but not Glom2, induced 21 morphological changes in mt-nucleoids. However, a synergistic effect for DNA condensation 22 was observed in vitro when the two proteins were mixed (Fig. 4Fg), and down-regulation of 23 both Gloms induced a more severe morphological change of the mt-nucleoid (Fig. 6A). 24 Although it is not clear whether the effect in the double down-regulation is direct or indirect, 25 similar synergistic effect for DNA condensation is also observed in histones in the nuclear 
1 chromatin. Nuclear DNA is wrapped around a particle of core histone octamer, and then the

2 nucleosomal particles are folded and condensed into a higher-order chromatin structure by

3 linker histones (Allan et al., 1986; Thoma et al., 1979; Wolffe, 1998). In this case, DNA-linker

4 histone interaction is important for facilitation of DNA condensation. It has been revealed that

5 the linker histone directly interacts with nucleosomal DNA and linker DNA adjacent to the

6 nucleosome core to fold nucleosomal particles (Brown et al., 2006; Zlatanova et al., 2008).

7 Since Glom and Glom2 have DNA binding ability, DNA-Gloms interactions may be important

8 for mtDNA condensation. In addition, it is possible that Glom-Glom2 interaction might also

9 facilitate mtDNA condensation. However, immunoprecipitation analysis could not clarify the

10 interaction between Glom and Glom2 because they tended to bind to beads for analysis

11 nonspecifically, whereas Far-western blotting analysis showed no interaction between Glom

12 and Glom2 (data not shown). From these considerations, one possibility is that Glom2 might

13 act to assemble the fundamental Glom-DNA complexes by its DNA binding ability and

14 contributes to the synergistic mtDNA condensation.

15 In wild type cell, the major axes length of mt-nucleoids is proportional to the copy 16 number of mtDNA in mt-nucleoids, and the minor axes length of mt-nucleoids is maintained 17 constant (Sasaki et al., 1998; Fig. 6B). However, down-regulation of Glom reduced the lengths 18 of both major and minor axes, and simultaneous down-regulation of both Glom and Glom2 19 induced a more severe morphological change of the mt-nucleoid (Fig. 6A, 6B). It might be 20 possible to assume that some topological change in packaging and coordination of mtDNA 21 affect morphology of mt-nucleoids. Huge mt-nucleoids also emerged in double down-regulated 22 cells. These results suggest that Glom and Glom2 are involved in the maintenance of the 23 architecture of whole mt-nucleoid.

24 In yeast cells lacking Abf2, the mt-nucleoid is diffuse and different from that of the wild 25 type (Newman et al., 1996). Our down-regulation experiments with P. polycephalum suggested 
1 more redundant mechanisms in the packaging of mtDNA. When we down-regulated Glom, we

2 could not detect a decrease in fluorescence intensity after DAPI staining, even though the

3 morphology of mt-nucleoids apparently changed. No diffuse mt-nucleoid was observed even

4 after down-regulation of both Gloms (Fig. 6A). These observations indicate that mtDNA was

5 still packed in a condensed state. Low amounts of Glom and Glom2, which were hardly

6 detectable in our Western blotting analysis (Fig. 5C), may have been enough for the packaging

7 of mtDNA. However, we speculate that other mt-nucleoid protein(s) might compensate for

8 Glom and Glom2. Miyakawa et al. (1995) reported in yeast that the packaging of mtDNA by

9 Abf2 was limited and that combination with other DNA-binding proteins with molecular

10 masses of 30-, 38-, 50-, 52-, and 67-kDa, was important for DNA compaction in the

11 mt-nucleoid. In our search for DNA-binding proteins involved in the packaging of mtDNA, 38-,

12 70-, and 90-kDa proteins were also good candidates although they showed slightly lower

13 affinity on the DNA-cellulose column than Glom and Glom2 (Fig. 1C and Table 1). Detailed

14 cytological analysis of the nucleoid structure, combined with down-regulation of $\mathrm{MO}$, will

15 clarify the possible existence of other DNA-packaging proteins.

16 The relationship in maintenance of mtDNA and HMG-type mtDNA packaging proteins has

17 been well characterized. In yeast, disruption of $A B F 2$ reduced mtDNA to $50 \%$ under

18 respiration-dispensable conditions or $0 \%$ under fermentable conditions (Diffley and Stillman,

19 1991; Zelenaya-Troitskaya et al., 1998). In animals, homozygous disruption of Tfam was lethal,

20 while heterozygous disruption decreased mtDNA to 50\% (Larsson et al., 1998; Matsushima et

21 al., 2003). RNAi knockdown or overexpression of TFAM showed a correlation between the

22 amount of mtDNA and TFAM (Goto et al., 2001; Matsushima et al., 2003; Ekstrand et al.,

23 2004; Kanki et al., 2004). These results indicate that the copy number of mtDNA depends on

24 the amount of Abf2 and TFAM. In P. polycephalum, down-regulation of Glom reduced the copy

25 number of mtDNA to $33 \%$ (Fig. 6C), which is consistent with previous reports on Abf2 and 
1 TFAM. Simultaneous down-regulation of both Gloms further reduced mtDNA to 5.5\% (Fig.

2 6C). Glom and Glom2 are suggested to work synergistically in the maintenance of mtDNA.

3 In Glom depressed cells, transcript accumulation level of all three genes decreased

4 probably due to the decrease of mtDNA copy number (Fig. 6C-6E). However, although

5 down-regulation of only Glom2 did not cause apparent defects in the copy number of mtDNA

6 and the mt-nucleoid structure, transcripts level of cox1 and nad7 were significantly impaired

7 (Fig. 6D, 6E). Interestingly, the accumulation of nad6 transcripts was not impaired by Glom2

8 down-regulation. Glom2 is suggested to be a novel DNA-packaging protein that effects on the

9 transcripts level of some genes in the mt-nucleoid. This also implies that Glom 2 is not simply

10 an accessory factor of Glom. Two possibilities exist for the decreased mRNA accumulation:

11 one is that stabilization of mRNA was defective, and the other is that transcription was

12 suppressed. Since smear degradation products were not detected in our Northern blot analysis

13 (data not shown), Glom2 might not be involved in the stabilization of mRNA. Therefore,

14 Glom2 might be involved in the transcriptional regulation of some mitochondrial genes.

15 Further investigation might provide a specific function of Glom2 in the future.

16 Glom2 is partly homologous with Mgm101 of budding yeast, which was identified in a

17 genetic screen for mutants that causes loss of mtDNA (Chen et al., 1993). Some properties of

18 Mgm101 and Glom2 resemble each other. In organellar formaldehyde-cross-linking studies,

19 Mgm101 is an abundant mtDNA-associated protein in yeast (Kaufman et al., 2000), but its

20 ability for mtDNA packaging is unknown. A lack of MGM101 did not cause significant changes

21 in the nucleoid structure in yeast cells (Meeusen et al., 1999). Mgm101 has been suggested to

22 be involved in repair of oxidatively damaged mtDNA (Meeusen et al., 1999) and is known as a

23 putative replication initiator in budding yeast (Zuo et al., 2002). In P. polycephalum, oxidative

24 stress increased the expression of Glom2 (Itoh, unpublished data), implying the possibility that

25 Glom2 might also be involved in the repair of oxidatively damaged mtDNA, like Mgm101. In 
1 contrast, Mgm101 has some different properties compared to Glom2. Mgm101 is present only

2 in a subpopulation of mt-nucleoids (Meeusen and Nunnari, 2003), and MGM101 deletion

3 mutants cause loss of mtDNA (Chen et al., 1993). These different properties imply that

4 Mgm101 is not an ortholog of Glom2, although further analysis is required to elucidate this

5 point. No matter how Glom2 and Mgm101 are related, the wide distribution of MGM101-like

6 genes in eukaryotic cells, possibly mitochondria of eukaryotic cells, may suggest an important

7 function in mitochondria.

8 Down-regulation with MOs provided a powerful method to investigate the function of 9 mt-nucleoid proteins of P. polycephalum. Since the plasmodium is a giant multinucleate cell, 10 we could obtain enough material for biochemical and molecular genetic analyses after a single 11 injection. Time-course analysis of a single cell by Western blotting was also possible. Moreover, 12 retaining a decreased expression level was possible by re-injecting MOs, and examining many 13 genes at the same time should also be possible by mixing MOs for the down-regulation of 14 multiple target genes. The mt-nucleoid of $P$. polycephalum consists of more than 70 15 mt-nucleoid proteins (Sasaki et al., 2003). Analysis of all these is now in progress using pure 16 isolated mt-nucleoids. Our finding of two mitochondrial DNA-packaging proteins should 17 provide the basis for such future studies in P. polycephalum. Furthermore, our novel model 18 suggesting that plural DNA-packaging proteins organize the mt-nucleoid may provide insights 19 for the study of mt-nucleoids in other organisms. 


\section{Acknowledgements}

2 We thank Dr. Minako Ueda (Nagoya University) for stimulating discussions and helpful

3 advices, Dr. Kiyotaka Hitomi (Nagoya University) for providing the anti-ANT antibody, and

4 Mr. Hiroki Tsutsui (Nagoya University) for help with the phylogenetic analysis. This work was

5 supported by a Grant from the Japan Society for the Promotion of Science Fellowships (11886

6 to KI), a Grant-in-Aid for Creative Scientific Research (18GS0314-01 to NS), and Japan NEXT

7 Grant-in-Aid for Young Scientists (Start-up:20870020 and B:21770041 to M.M.K.).

\section{References}

10 Allan, J., Mitchell, T., Harborne, N., Bohm, L., Crane-Robinson, C., 1986. Roles of H1 11 domains in determining higher order chromatin structure and H1 location. J. Mol. Biol. $187,591-601$.

Antoshechkin, I., Bogenhagen, D.F., 1995. Distinct roles for two purified factors in transcription of Xenopus mitochondrial DNA. Mol. Cell. Biol. 15, 7032-7042.

Berger, K.H., Yaffe, M.P., 1998. Prohibitin family members interact genetically with mitochondrial inheritance components in Saccharomyces cerevisiae. Mol. Cell. Biol. 18, 4043-4052.

Bogenhagen, D.F., Rousseau, D., Burke, S., 2008. The layered structure of human mitochondrial DNA nucleoids. J. Biol. Chem. 283, 3665-3675.

Bonawitz, N.D., Clayton, D.A., Shadel, G.S., 2006. Initiation and beyond: multiple functions of the human mitochondrial transcription machinery. Mol. Cell 24, 813-825.

Brewer, L.R., Friddle, R., Noy, A., Baldwin, E., Martin, S.S., Corzett, M., Balhorn, R., Baskin, R.J., 2003. Packaging of single DNA molecules by the yeast mitochondrial protein Abf2p. Biophys J. 85, 2519-2524.

Brown, D.T., Izard, T., Misteli, T., 2006. Mapping the interaction surface of linker histone 
1 H1(0) with the nucleosome of native chromatin in vivo. Nat. Struct. Mol. Biol. 13, $2250-255$.

3 Byrne, E.M., Visomirski-Robic, L., Cheng, Y.W., Rhee, A.C., Gott, J.M., 2007. RNA editing in 4 Physarum mitochondria: assays and biochemical approaches. Methods Enzymol. 424, 5

6 Chen, X.J., Guan, M.X., Clark-Walker, G.D., 1993. MGM101, a nuclear gene involved in 7

9 Chen, X.J., Wang, X., Kaufman, B.A., Butow, R.A., 2005. Aconitase couples metabolic maintenance of the mitochondrial genome in Saccharomyces cerevisiae. Nucleic Acids Res. 21, 3473-3477. regulation to mitochondrial DNA maintenance. Science 307, 714-717.

Daniel, J., Baldwin, H., 1964. Methods of culture for plasmodia1 myxomycetes., in: Prescott, D. (Ed.), Methods in Cell Physiology. Academic Press, New York, pp. 9-41.

Diffley, J.F., Stillman, B., 1991. A close relative of the nuclear, chromosomal high-mobility group protein HMG1 in yeast mitochondria. Proc. Natl. Acad. Sci. U.S.A. 88, 7864-7868.

Diffley, J.F., Stillman, B., 1992. DNA binding properties of an HMG1-related protein from yeast mitochondria. J. Biol. Chem. 267, 3368-3374.

Ekstrand, M.I., Falkenberg, M., Rantanen, A., Park, C.B., Gaspari, M., Hultenby, K., Rustin, P., Gustafsson, C.M., Larsson, N.G., 2004. Mitochondrial transcription factor A regulates mtDNA copy number in mammals. Hum. Mol. Genet. 13, 935-944.

Fisher, R.P., Clayton, D.A., 1988. Purification and characterization of human mitochondrial transcription factor 1. Mol. Cell. Biol. 8, 3496-3509.

Foury, F., 1989. Cloning and sequencing of the nuclear gene MIP1 encoding the catalytic subunit of the yeast mitochondrial DNA polymerase. J. Biol. Chem. 264, 20552-20560.

Foury, F., Lahaye, A., 1987. Cloning and sequencing of the PIF gene involved in repair and recombination of yeast mitochondrial DNA. EMBO. J. 6, 1441-1449. 
1 Friddle, R.W., Klare, J.E., Martin, S.S., Corzett, M., Balhorn, R., Baldwin, E.P., Baskin, R.J., 2 Noy, A., 2004. Mechanism of DNA compaction by yeast mitochondrial protein Abf2p. 3 Biophys. J. 86, 1632-1639.

4 Ghivizzani, S.C., Madsen, C.S., Nelen, M.R., Ammini, C.V., Hauswirth, W.W., 1994. In organello footprint analysis of human mitochondrial DNA: human mitochondrial transcription factor A interactions at the origin of replication. Mol. Cell. Biol. 14, $7717-7730$.

Goto, A., Matsushima, Y., Kadowaki, T., Kitagawa, Y., 2001. Drosophila mitochondrial transcription factor A (d-TFAM) is dispensable for the transcription of mitochondrial DNA in Kc167 cells. Biochem. J. 354, 243-248.

Gott, J.M., Parimi, N., Bundschuh, R., 2005. Discovery of new genes and deletion editing in Physarum mitochondria enabled by a novel algorithm for finding edited mRNAs. Nucleic Acids Res. 33, 5063-5072.

Gott, J.M., Visomirski, L.M., Hunter, J.L., 1993. Substitutional and insertional RNA editing of the cytochrome c oxidase subunit 1 mRNA of Physarum polycephalum. J. Biol. Chem. $268,25483-25486$.

Greenleaf, A.L., Kelly, J.L., Lehman, I.R., 1986. Yeast RPO41 gene product is required for transcription and maintenance of the mitochondrial genome. Proc. Natl. Acad. Sci. U.S.A. 83, 3391-3394.

Haindl, M., Holler, E., 2005. Use of the giant multinucleate plasmodium of Physarum polycephalum to study RNA interference in the myxomycete. Anal. Biochem. 342, 194-199.

Hines, J.C., Ray, D.S., 1998. The Crithidia fasciculata KAP1 gene encodes a highly basic protein associated with kinetoplast DNA. Mol. Biochem. Parasitol. 94, 41-52.

Itoh, K., Izumi, A., Mori, T., Dohmae, N., Yui, R., Maeda-Sano, K., Kanaoka, M., Kuroiwa, H., 
1 Kuroiwa, T., Higashiyama, T., Murakami-Murofushi, K., Kawano, S., Sasaki, N., 2009.

2 New protein Pmn34 with an exonuclease motif localizes in the mitochondrial nucleoid 3 periphery of Physarum polycephalum. Cytologia 74, 401-407.

4 Kanki, T., Ohgaki, K., Gaspari, M., Gustafsson, C.M., Fukuoh, A., Sasaki, N., Hamasaki, N., 5 Kang, D., 2004. Architectural role of mitochondrial transcription factor A in maintenance 6 of human mitochondrial DNA. Mol. Cell. Biol. 24, 9823-9834.

7 Karkare, S., Bhatnagar, D., 2006. Promising nucleic acid analogs and mimics: characteristic features and applications of PNA, LNA, and morpholino. Appl. Microbiol. Biotechnol. 71, 575-586.

Kaufman, B.A., Durisic, N., Mativetsky, J.M., Costantino, S., Hancock, M.A., Grutter, P., Shoubridge, E.A., 2007. The mitochondrial transcription factor TFAM coordinates the assembly of multiple DNA molecules into nucleoid-like structures. Mol. Biol. Cell 18, $3225-3236$.

Kaufman, B.A., Newman, S.M., Hallberg, R.L., Slaughter, C.A., Perlman, P.S., Butow, R.A., 2000. In organello formaldehyde crosslinking of proteins to mtDNA: identification of bifunctional proteins. Proc. Natl. Acad. Sci. U.S.A. 97, 7772-7777.

Kawano, S., Anderson, R.W., Nanba, T., Kuroiwa, T., 1987. Polymorphism and uniparental inheritance of mitochondrial DNA in Physarum polycephalum. J. Gen. Microbiol. 133, $3175-3182$.

Khorasanizadeh, S., 2004. The nucleosome: from genomic organization to genomic regulation. Cell 116, 259-272.

Kucej, M., Butow, R.A., 2007. Evolutionary tinkering with mitochondrial nucleoids. Trends Cell Biol. 17, 586-592.

Kuroiwa, T., 1974. Studies on mitochondrial structure and function in Physarum polycephalum. III. Electron microscopy of a large amount of DNA releases from a central body in 
1 mitochondria by trypsin digestion. J. Cell Biol. 63, 299-306.

2 Kuroiwa, T., 1982. Mitochondrial nuclei. Int. Rev. Cytol. 75, 1-59.

3 Larsson, N.G., Garman, J.D., Oldfors, A., Barsh, G.S., Clayton, D.A., 1996. A single mouse

4 gene encodes the mitochondrial transcription factor $\mathrm{A}$ and a testis-specific nuclear

$5 \quad$ HMG-box protein. Nat. Genet. 13, 296-302.

6 Larsson, N.G., Wang, J., Wilhelmsson, H., Oldfors, A., Rustin, P., Lewandoski, M., Barsh,

7 G.S., Clayton, D.A., 1998. Mitochondrial transcription factor A is necessary for mtDNA

8 maintenance and embryogenesis in mice. Nat. Genet. 18, 231-236.

9 MacAlpine, D.M., Perlman, P.S., Butow, R.A., 1998. The high mobility group protein Abf2p

10 influences the level of yeast mitochondrial DNA recombination intermediates in vivo.

11 Proc. Natl. Acad. Sci. U.S.A. 95, 6739-6743.

12 Matsushima, Y., Matsumura, K., Ishii, S., Inagaki, H., Suzuki, T., Matsuda, Y., Beck, K.,

13 Kitagawa, Y., 2003. Functional domains of chicken mitochondrial transcription factor A

14 for the maintenance of mitochondrial DNA copy number in lymphoma cell line DT40. J.

$15 \quad$ Biol. Chem. 278, 31149-31158.

McCulloch, V., Shadel, G.S., 2003. Human mitochondrial transcription factor B1 interacts with the C-terminal activation region of h-mtTFA and stimulates transcription independently of its RNA methyltransferase activity. Mol. Cell. Biol. 23, 5816-5824.

Meeusen, S., Nunnari, J., 2003. Evidence for a two membrane-spanning autonomous mitochondrial DNA replisome. J. Cell Biol. 163, 503-510.

Meeusen, S., Tieu, Q., Wong, E., Weiss, E., Schieltz, D., Yates, J.R., Nunnari, J., 1999. Mgm101p is a novel component of the mitochondrial nucleoid that binds DNA and is required for the repair of oxidatively damaged mitochondrial DNA. J. Cell Biol. 145, 291-304.

Megraw, T.L., Chae, C.B., 1993. Functional complementarity between the HMG1-like yeast 
3 Miyakawa, I., Fumoto, S., Kuroiwa, T., Sando, N., 1995. Characterization of DNA-binding 4 proteins involved in the assembly of mitochondrial nucleoids in the yeast Saccharomyces $5 \quad$ cerevisiae. Plant Cell Physiol. 36, 1179-1188.

6 Newman, S.M., Zelenaya-Troitskaya, O., Perlman, P.S., Butow, R.A., 1996. Analysis of 7 mitochondrial DNA nucleoids in wild-type and a mutant strain of Saccharomyces cerevisiae that lacks the mitochondrial HMG box protein Abf2p. Nucleic Acids Res. 24, 386-393.

Ohta, T., Kawano, S., Kuroiwa, T., 1993. Restriction of Amoebo-Flagellate (AF) Transformation to Interphase Is Related to M Phase Replication of the Centrosome Complex in the Amoebae of the True Slime Mould, Physarum polycephalum: A Three-Dimensional Approach. J. Struct. Biol. 111, 105-117.

Parisi, M.A., Clayton, D.A., 1991. Similarity of human mitochondrial transcription factor 1 to high mobility group proteins. Science 252, 965-969.

Perriere, G., Gouy, M., 1996. WWW-query: an on-line retrieval system for biological sequence banks. Biochimie 78, 364-369.

Pinchai, N., Lee, B.S., Holler, E., 2006. Stage specific expression of poly(malic acid)-affiliated genes in the life cycle of Physarum polycephalum. Spherulin $3 \mathrm{~b}$ and polymalatase. FEBS J. 273, 1046-1055.

Sasaki, N., Kuroiwa, H., Nishitani, C., Takano, H., Higashiyama, T., Kobayashi, T., Shirai, Y., Sakai, A., Kawano, S., Murakami-Murofushi, K., Kuroiwa, T., 2003. Glom is a novel mitochondrial DNA packaging protein in Physarum polycephalum and causes intense chromatin condensation without suppressing DNA functions. Mol. Biol. Cell 14, $4758-4769$. 
1 Sasaki, N., Sakai, A., Kawano, S., Kuroiwa, H., Kuroiwa, T., 1998. DNA synthesis in isolated 2 mitochondrial nucleoids from plasmodia of Physarum polycephalum. Protoplasma 203, $3221-231$.

4 Schmid, M.B., 1990. More than just "histone-like" proteins. Cell 63, 451-453.

5 Spelbrink, J.N., 2010. Functional organization of mammalian mitochondrial DNA in nucleoids:

6 history, recent developments, and future challenges. IUBMB Life 62, 19-32.

7 Suzuki, T., Kawano, S., Kuroiwa, T., 1982. Structure of three-dimensionally rod-shaped mitochondrial nucleoids isolated from the slime mould Physarum polycephalum. J. Cell. Sci. 58, 241-261.

Takamatsu, C., Umeda, S., Ohsato, T., Ohno, T., Abe, Y., Fukuoh, A., Shinagawa, H., Hamasaki, N., Kang, D., 2002. Regulation of mitochondrial D-loops by transcription factor A and single-stranded DNA-binding protein. EMBO Rep. 3, 451-456.

Takano, H., Abe, T., Sakurai, R., Moriyama, Y., Miyazawa, Y., Nozaki, H., Kawano, S., Sasaki, N., Kuroiwa, T., 2001. The complete DNA sequence of the mitochondrial genome of Physarum polycephalum. Mol. Gen. Genet. 264, 539-545.

Thoma, F., Koller, T., Klug, A., 1979. Involvement of histone H1 in the organization of the nucleosome and of the salt-dependent superstructures of chromatin. J. Cell Biol. 83, $403-427$.

Van Dyck, E., Foury, F., Stillman, B., Brill, S.J., 1992. A single-stranded DNA binding protein required for mitochondrial DNA replication in S. cerevisiae is homologous to E. coli SSB. EMBO J. 11, 3421-3430.

Wada, F., Hasegawa, H., Nakamura, A., Sugimura, Y., Kawai, Y., Sasaki, N., Shibata, H., Maki, M., Hitomi, K., 2007. Identification of substrates for transglutaminase in Physarum polycephalum, an acellular slime mold, upon cellular mechanical damage. FEBS J. 274, $2766-2777$. 
1 Wang, Y., Bogenhagen, D.F., 2006. Human mitochondrial DNA nucleoids are linked to protein

2 folding machinery and metabolic enzymes at the mitochondrial inner membrane. J. Biol.

3 Chem. 281, 25791-25802.

4 Wolffe, A., 1998. Chromatin: Structure and Function. Academic Press, San Diego.

5 Xu, C.W., Hines, J.C., Engel, M.L., Russell, D.G., Ray, D.S., 1996. Nucleus-encoded histone

6 H1-like proteins are associated with kinetoplast DNA in the trypanosomatid Crithidia 7 fasciculata. Mol. Cell. Biol. 16, 564-576.

8 Yoshida, Y., Izumi, H., Torigoe, T., Ishiguchi, H., Itoh, H., Kang, D., Kohno, K., 2003. P53

9 physically interacts with mitochondrial transcription factor A and differentially regulates 10 binding to damaged DNA. Cancer Res. 63, 3729-3734.

11 Zelenaya-Troitskaya, O., Newman, S.M., Okamoto, K., Perlman, P.S., Butow, R.A., 1998. Genetics 160, 1389-1400. 


\section{$1 \quad$ Figure captions}

2

$3 \quad$ Figure 1.

4 Analysis of mtDNA-binding proteins in the isolated mt-nucleoid.

5 (A) SDS-PAGE analysis of mt-nucleoid proteins released from mtDNA by treatment with

6 various concentrations of $\mathrm{NaCl}(0,0.1,0.2,0.5,1.0 \mathrm{M})$. (B) SDS-PAGE analysis of mt-nucleoid

7 proteins released from mtDNA by treatment with $(+)$ or without $(-)$ DNase I $(0.01 \mathrm{mg} / \mathrm{ml})$. The

8 isolated mt-nucleoid after treatment with $\mathrm{NaCl}$ or DNase I was centrifuged at $18,500 \times g$ for 20

$9 \min$ at $4^{\circ} \mathrm{C}$. Proteins from pelletable and supernatant fractions of the mt-nucleoid were

10 subjected to SDS-PAGE. (C) SDS-PAGE analysis of mt-nucleoid proteins bound to the

11 DNA-cellulose column. The proteins of the isolated mt-nucleoid were applied to a

12 DNA-cellulose column, and bound proteins were eluted with $\mathrm{NaCl}(0.1,0.2,0.3,0.4,1.0,2.0$

13 M). Proteins from the mt-nucleoid (MN, lane 1) and eluted fractions (lanes 2-7) were analyzed

14 by SDS-PAGE. The band just under $34-\mathrm{kDa}(*)$ was a degradation product of Glom.

15

Figure 2.

(A) Alignment of amino acid sequences of the N-terminal region of Pmn56 and Mgm101 homologs from five major species of fungi including yeast, Dictyostelium discoideum, and two animal sequences. Identical residues are indicated by black shading, and residues in more than $50 \%$ are indicated by gray shading. (B) Pmn56 has an additional region in the C-terminal including three polyprolines compared to yeast Mgm101s. Other organisms, except for yeast, tend to have similar additional C-terminal regions. (C) Molecular phylogeny of Pmn56 and Mgm101 of various organisms. Shown is a neighbor-joining tree based on the Mgm101 domain. Branch length reflects the number of amino acid changes. Bootstrap values (\%) for 100 replications are indicated on each node. 


\section{$2 \quad$ Figure 3.}

3 Intercellular localization of Pmn56 to the mt-nucleoid.

4 (A) Immunoblot analysis of cell fractionation using the anti-Pmn56 antibody. After treatment

5 of isolated mitochondria with NP-40 and centrifugation, the mt-nucleoid fraction was obtained

6 in the pelletable fraction, and the mitochondrial membrane and matrix fraction were in the

7 supernatant fractions. One microgram of proteins of the whole cell (lane 1), isolated

8 mitochondria (Mt, lane 2), the mitochondrial supernatant fraction after treatment with NP-40

9 (Mt-sup, lane 3), and isolated mt-nucleoids (MN, lane 4) were separated by SDS-PAGE and

10 analyzed by immunoblotting using anti-Pmn56 antibody. (B) Immunofluorescence micrograph

11 showing the localization of Pmn56 to mt-nucleoids. The amoeba cell was stained with DAPI

12 (left). The same cell was also stained with anti-Pmn56 antibody and Alexa-conjugated second

13 antibody (right). Scale bar, $5 \mu \mathrm{m}$.

\section{$15 \quad$ Figure 4.}

16 In vitro functional analyses of Pmn56 for nucleotides.

17 (A) Constructs of recombinant Pmn56. Pmn56m is a mature form of Pmn56 that had the 18 mitochondrial targeting peptide removed. (B) Coomassie-stained gel after SDS-PAGE of the 19 purified Pmn56m (1 $\mu \mathrm{g})$. (C) DNA mobility shift assay of Pmn56m using XbaI-digested 20 mtDNA. Each digested mtDNA (200 ng) was incubated without (-) or with various 21 concentrations $(4.0,2.0,1.0,0.5 \mu \mathrm{M})$ of Pmn56m and BSA as described in the Materials and 22 Methods. (D) RNA mobility shift assay of Pmn56m and Glom using mitochondrial RNA. Each 23 mitochondrial RNA (200 ng) was incubated without (-) or with various concentrations (8.0, 4.0, $242.0,1.0,0.5 \mu \mathrm{M})$ of Pmn56m and Glom, RNase, and BSA as described in the Materials and 25 Methods (E) DAPI-fluorescence micrographs showing the reassembly of mt-nucleoids by 
1 dialysis. The isolated mt-nucleoids $(5 \mu \mathrm{g})$ were disassembled at $0.3 \mathrm{M} \mathrm{NaCl}$ and then $0.3 \mathrm{M}$

$2 \mathrm{NaCl}$ supernatant-depleted fractions were prepared as described by Sasaki et al. (2003). 0.3M

$3 \mathrm{NaCl}$ disassembled mt-nucleoids fraction (a), 0.3 M-NaCl supernatant-depleted fraction (b),

4 and $0.3 \mathrm{M} \mathrm{NaCl}$ supernatant-depleted fraction with $1 \mu \mathrm{g}$ of Glom (c), or $0.25 \mu \mathrm{g}$ (d) of Pmn56m

5 (h), were dialyzed against NE1-S buffer. Scale bar, $2 \mu \mathrm{m}$. (F) DNA condensation ability of

6 Pmn56 and Glom. Each mtDNA (450 ng) was incubated with Pmn56m (a-c) or Glom (d-f) at

7 protein concentrations of $0.5 \mu \mathrm{M}(\mathrm{a}, \mathrm{d}), 2.5 \mu \mathrm{M}(\mathrm{b}, \mathrm{e})$, or $5.0 \mu \mathrm{M}(\mathrm{c}, \mathrm{f})$. Incubation with Pmn56

8 and Glom at concentrations of $0.5 \mu \mathrm{M}$ and $2.5 \mu \mathrm{M}$, respectively, induced high condensation of

9 mtDNA (g). BSA (h) and free protein (i) were used as controls. Resultant DNA was examined

10 by DAPI fluorescence microscopy. Scale bar, $5 \mu \mathrm{m}$.

$12 \quad$ Figure 5.

13 Down-regulation method for targeted genes using morpholino antisense oligos (MOs).

14 (A) MOs labeled with FITC were injected into the plasmodium. The same plasmodium 15 immediately and $2 \mathrm{~h}$ after injection. Just after injection, FITC fluorescence appeared to spread 16 along veins instantaneously. Two hours later, FITC fluorescence spread throughout the cell.

17 Scale bar, $1 \mathrm{~cm}$. (B) The scheme of injection. MOs were re-injected to the plasmodium 5.5 days 18 after the first injection, and the plasmodium was subcultured every 3 days. (C) MOs (Glom MO, 19 Glom2 MO, and Glom + Glom2 MOs) were injected or not injected (W/O) into the 20 plasmodium. Twelve days after the first injection, cells were sampled and analyzed. Amount of 21 Glom2, Glom, and ANT protein (ANT: as a control of mitochondrial amount) in total cells (16 $22 \mu \mathrm{g}$ ) was analyzed by Western blotting. Amount of actin protein (as a control of cell amount) in 23 total cells $(12 \mu \mathrm{g})$ was analyzed by SDS-PAGE. The lower band detected by anti-Glom 24 antibody was the degradation product of Glom. (D) A 4- $\mathrm{cm}^{2}$ area of the plasmodium was placed 25 on a new plate 12 days after the first injection, and then 3-day cultured plates were observed. 


\section{$2 \quad$ Figure 6.}

3 Effect of down-regulation of Gloms on the mt-nucleoid morphology and the level of mtDNA

4 and mtDNA transcripts.

5 (A) Plasmodium injected or not injected with MOs were stained with DAPI and observed by

6 fluorescence and phase contrast microscopy. The lower panels were enlarged images of 7 mitochondria. Scale bar, $5 \mu \mathrm{m}$. (B) Lengths of the major and minor axes of mt-nucleoids were

8 measured with ImageJ and plotted $(n=200)$. (C) mtDNA copy number measured by

9 quantitative real-time PCR. At 12 days after the first injection, total genome was extracted from

10 the Plasmodium injected or not injected with MOs and subjected to real-time PCR. The copy

11 number of mtDNA was estimated using primers for the rRNA gene on the mitochondrial

12 genome and was normalized using primers for the nuclear-encoded Glom gene. ${ }^{* *} P<0.001$, *

$13 P<0.003$ versus $\mathrm{W} / \mathrm{O}$ control. Values are mean \pm SE. (D) Northern blot analysis showing the

14 level of mtDNA transcripts. At 12 days after the first injection, total RNA was extracted from

15 the Plasmodium injected or not injected with MOs and subjected to Northern blot analysis. The

16 blots were hybridized with a gene-specific DNA probe for cox1, nad6, and nad7. The full

17 mRNA length of cox1, nad6, and nad7 are 1785, 498, and 1206 base, respectively. Signals by

18 Cox 1 or nad7 probe were detected as a similar size as their mRNAs. Cox6 signal was detected

19 larger than its mRNA because it was cotranscripted with adjacent genes. The lower panels are

20 rRNAs stained with ethidium bromide as loading controls. (E) The level of mtDNA transcripts

21 measured by real-time RT-PCR. The transcripts levels were estimated using primers for cox1,

22 nad6, and nad7 mtDNA fragments individually and were normalized using primers for 23 nuclear-encoded GAPDH gene. 
Figures

\section{Figure 1.}

A

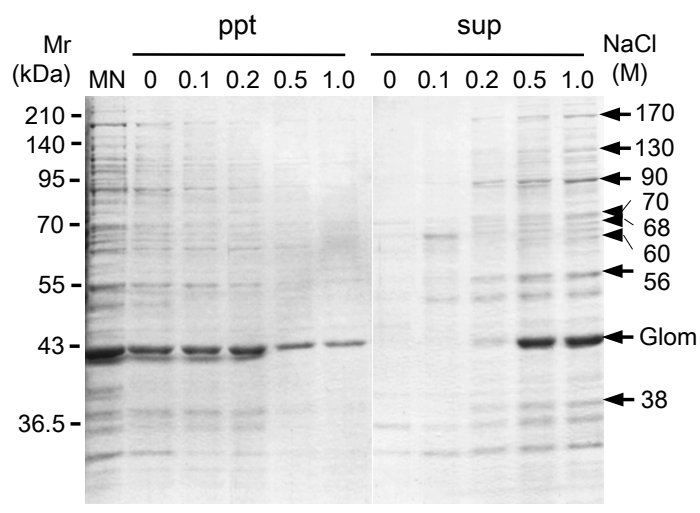

B

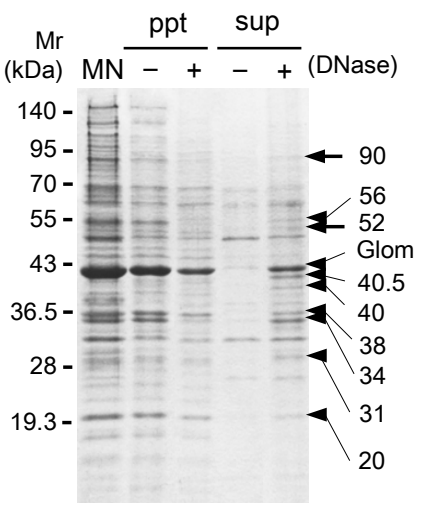

C

$\mathrm{Mr} \quad \mathrm{NaCl}$

(kDa) $\quad$ MN $\begin{array}{lllllll}0.1 & 0.2 & 0.3 & 0.4 & 1.0 & 2.0 & \text { (M) }\end{array}$

140 -

$95-\square \quad \longrightarrow 95$

$70->>70$

$55-$ - $>56$

$43- \pm-\infty \mathrm{Glom}$

$36.5-\quad *-\quad-\quad 38$

$28-$

$19.3-$ 


\section{Figure 2.}

\section{A}

Physarum

Dictyostelium

Schizosaccha

Aspergillus

Saccharomyces

Candida

Nematostella

Trichoplax

Physarum

Dictyostelium

Schizosacchar

Cryptococcus

Aspergillus

Saccharomyces

Candida

Nematostella

Trichoplax

Physarum

Dictyostelium

Schizosacchar

Cryptococcus

Aspergillus

Candida

Nematostella

Trichoplax

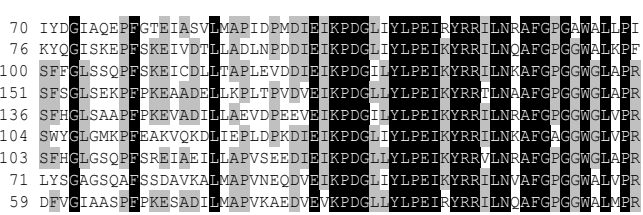

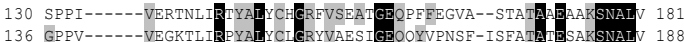

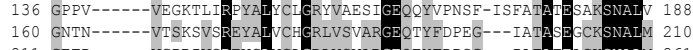
211 GETD------VGPRIVSREWGLVCLGRIVSVARGEQEYFDPSG---IATATEACKSNALM 261 196 SESI-----VTPRTVTREYALVCNGRLVSVARGE D DYFTPDG---IPTATEGCRSNALV $246 \quad$ C 163 TESL-----VTSGQI

131 GDSLQFQSEKDNSQLIVREYALECERFASOATGEHTFYSNNGNMVYGKA IDSAKSNALM 190 182 RCCKDLGIGSELWDEFFIFDWKKKYYSVEVQCSNMKNTNDRRRLWRRKDR--PPFEWPWKE 239
189 RCCKDLGIGSSLWDPIIFIRQWKSEYATERWCENSK-TKERRLFWELSNRSENQLPYPWKE 247 11 RCCKDLGVASELWDPRY IRVEKRENCVEVFVENV-LTKKRRKLW-RRKEDKFS--YPYKE 266

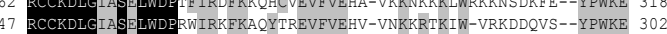
215 RCCKDLGVGSELWDFVFIKKFKVDHCT EKFVEHV-TTKRKKKIW-LRKDRQVE--YPYK- 269 5 RCCKDLGIA SELWDPSFIRRWKKKYCEEIFVEHV-NTKKKKKIWKLKSIKTVD--YPYRM 27 191 RCCKDLGVASELWDPQDYGANPSHYTLRSEYTPDI DKELRIFEGQRGCPRKVFFSHRAIS 250

\section{B}

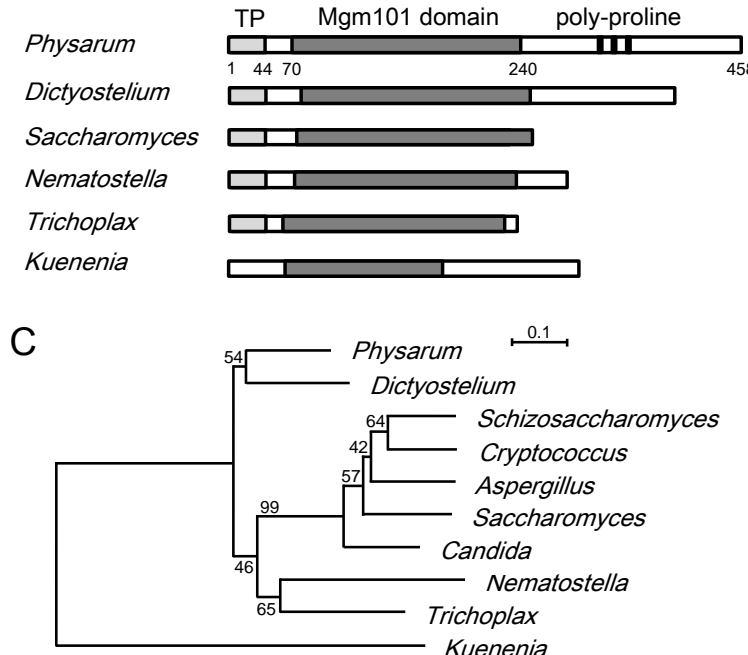


Figure 3.

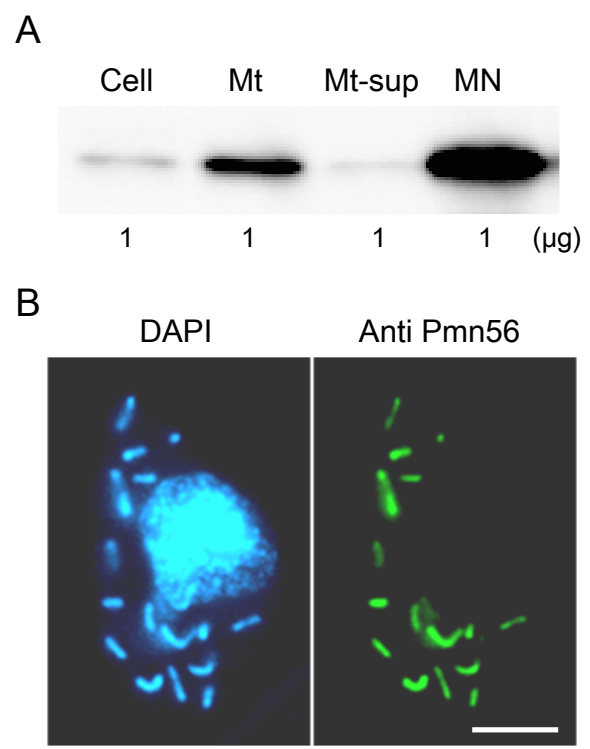


Figure 4.

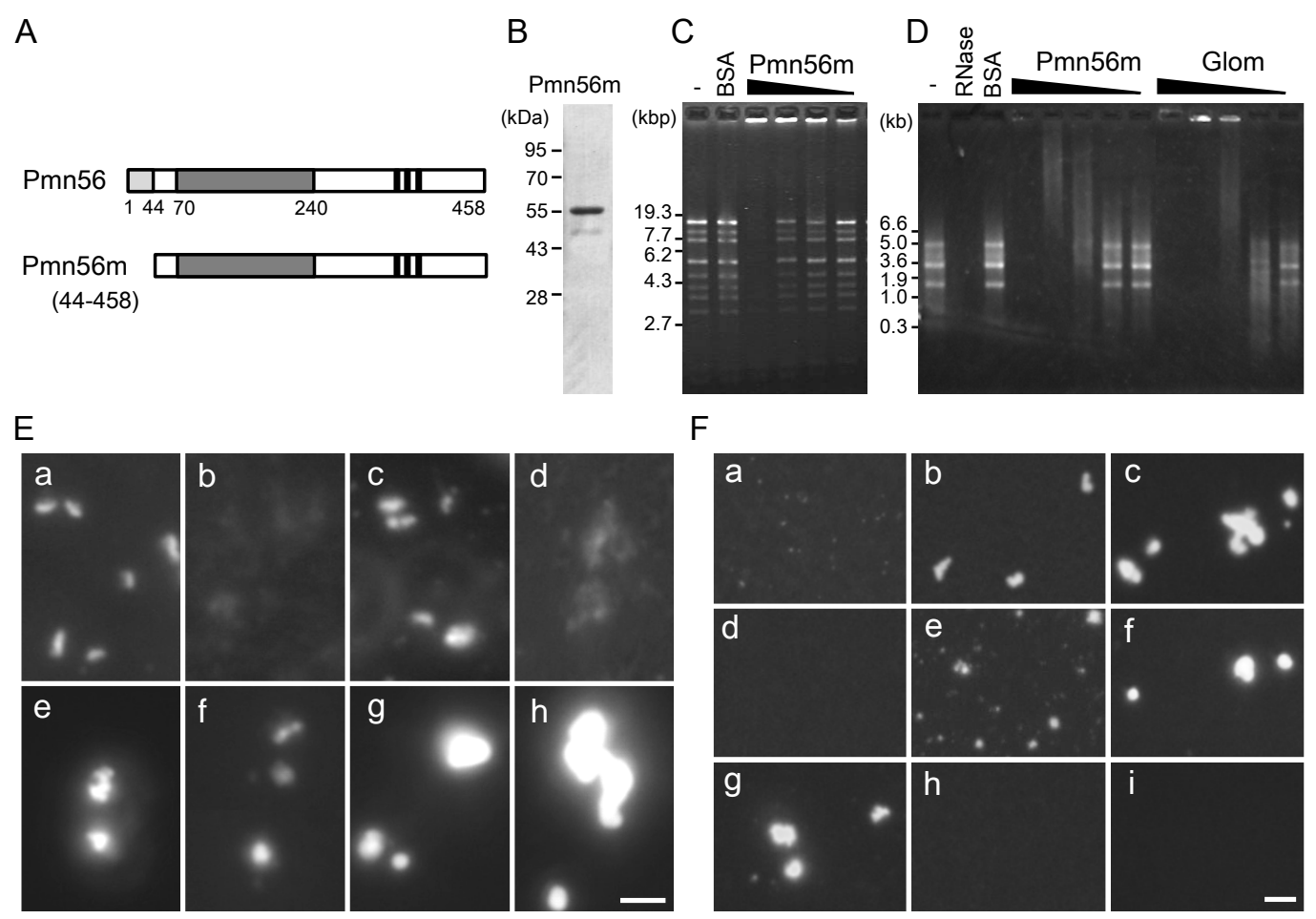


Figure 5.

A

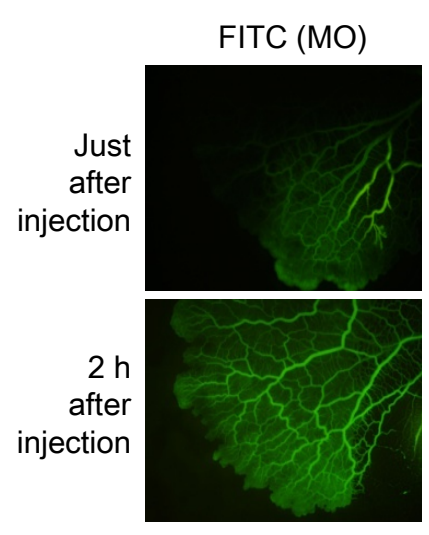

C

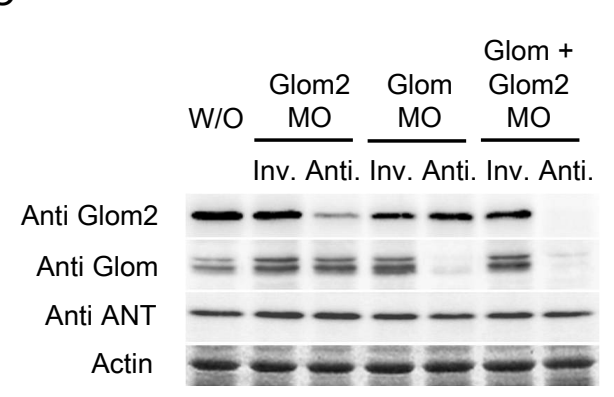

B

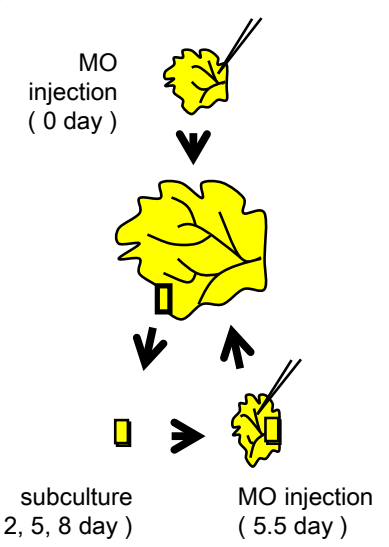

( $2,5,8$ day )

( 5.5 day )

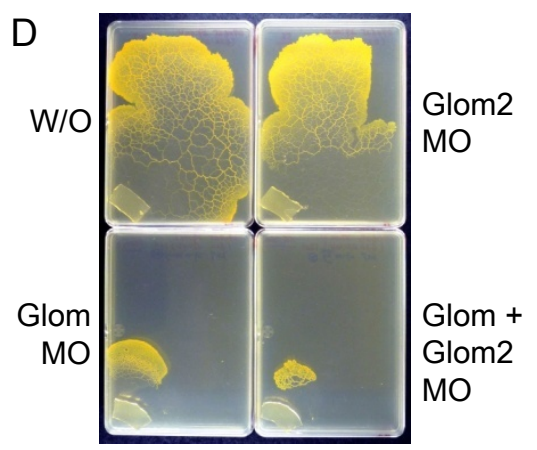


Figure 6.

A

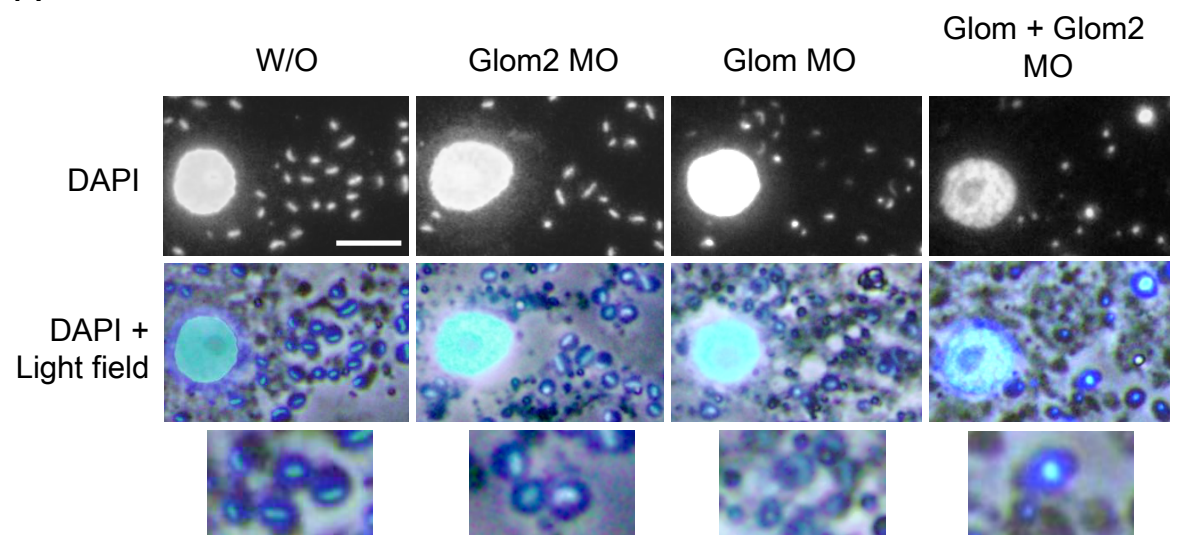

C

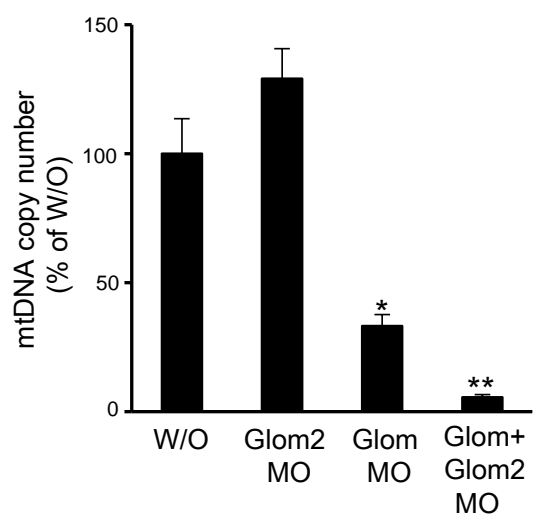

B
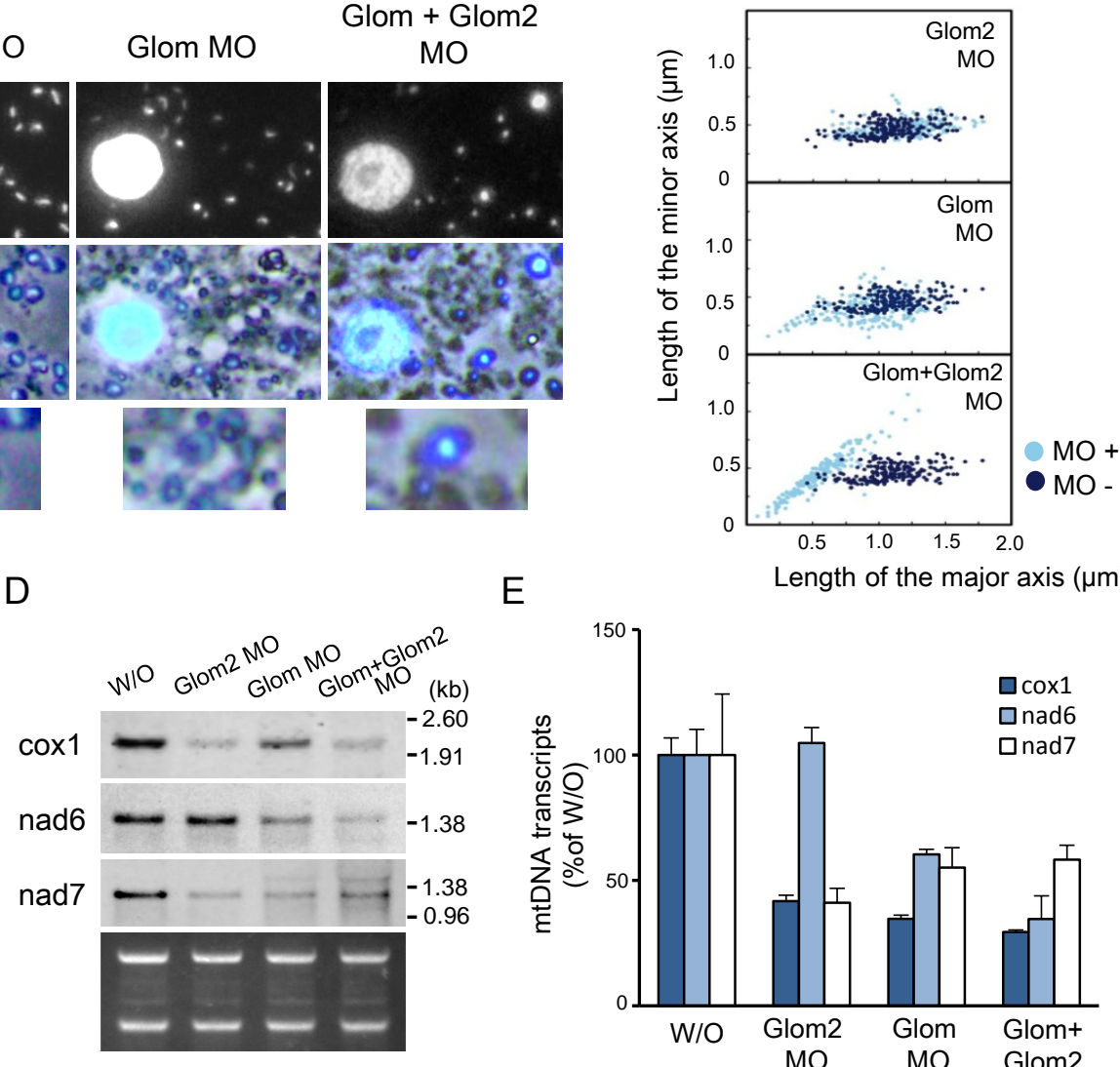

E

Length of the major axis $(\mu \mathrm{m})$

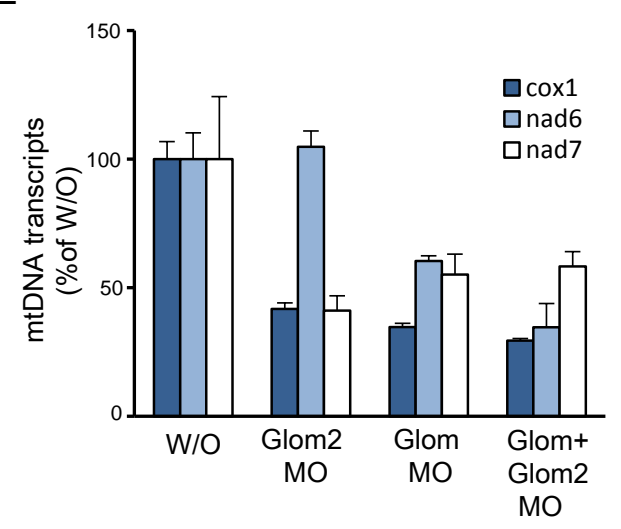


Table 1. The candidates for mtDNA-binding proteins in the isolated mt-nucleoid

\begin{tabular}{ll}
\hline \multicolumn{1}{c}{ Types of experiments } & \multicolumn{1}{c}{ Identified protein $(\mathrm{kDa})$} \\
\hline NaCl treatment of mt-nucleoids & Glom, 38, 56, 60, 68, 70, 90, 130, 170 \\
DNase treatment of mt-nucleoids & Glom, 20, 31, 34, 38, 40, 40.5, 52, 56, 90 \\
DNA cellulose column chromatography & Glom, 34, 38, 56, 70, 95 \\
$(0.3 \mathrm{M} \mathrm{NaCl})$ & \\
$(0.4 \mathrm{M} \mathrm{NaCl})$ & Glom, 56 \\
\hline
\end{tabular}

